\title{
As Good as the Networks They Keep?: Improving Outcomes through Weak Ties in Rural Uganda*
}

\author{
Kathryn N. Vasilaky* Kenneth L. Leonard ${ }^{\dagger}$
}

October 22, 2016

*Forthcoming, Economic Development and Cultural Change

\begin{abstract}
We examine an intervention randomized at the village level in which female farmers invited to a single training session were randomly paired with farmers whom they did not know and encouraged to share new agricultural information throughout the growing season for a recently adopted cash crop. We show that the intervention significantly increased the productivity of all farmers except of those who were already in the highest quintile of productivity, and that there were significant spillovers in productivity to male farmers.
\end{abstract}

\section{Introduction}

Programs aimed at increasing agricultural productivity are regarded as some of the most powerful means to reduce poverty [Asfaw et al., 2011, Thirtle et al., 2001]. Essential elements in the early stages of such programs are the dissemination of information from centers of science and research to subsistence farmers and the subsequent diffusion of this new knowledge within a village. Thus, the effectiveness of agricultural extension depends not only on the technical merits of a new technology but on the quality of the interactions between extension agents and the farmers whom they train, as well as the subsequent interactions between trained and untrained farmers (Anderson and Feder [2007, pp.2346] and Foster and Rosenzweig [1995]). Despite significant effort and money devoted to programs that expect a few select individuals who are trained to disseminate information to the remainder of the village, many studies over the past forty years

\footnotetext{
*Columbia University, Earth Institute, 2910 Broadway Hogan Hall, New York, NY 10025, (e-mail: knv4@columbia.edu)

${ }^{\dagger}$ Agricultural and Resource Economics, University of Maryland
} 
have documented a poor retention of learned information and even poorer diffusion of information across farmers, exacerbating poverty for the poorest individuals both in terms of productivity and in social capital [Feder et al., 2004, Leonard, 1977, Sinha and Mehta, 1972]. For example, Sinha and Mehta [1972] report that farmers who learned about a new innovation passed on only $28 \%$ of what they had learned to the farmers to whom they directly. In contrast, Conley and Udry [2010] report that Ghanaian pineapple farmers were able to improve yields through contact with farmers in their own social network, suggesting that diffusion does not necessarily occur across an entire village network, but is specific to each individual's own network. Indeed, belonging to strong social networks is correlated with earlier adoption of innovations and better outcomes [see Isham, 2002, Munshi, 2004, for example].

Unfortunately, although the poorest farmers frequently stand to benefit the most from new technologies, they are often outside of the very networks that would allow them to learn about these innovations. This is particularly true of women, who provide a significant amount of labor to African agriculture, are responsible for most food crop production, and typically experience significantly lower yields than men, even for the same crops [Quisumbing, 2003, Udry, 1996, Udry and Goldstein, 2006]. At the same time, there is evidence that networks of females are typically less oriented towards cash crops than those of males [Edmeades et al., 2008, Katungi et al., 2008]. Thus, women may suffer from large "structural holes" in their production networks [Hoang et al., 2006] and this could explain at least part of their lower productivity. This suggests that agricultural extension programs could be augmented by attempts to improve the dissemination of information to women and the subsequent dissemination of information within women's production networks.

This study evaluates an extension program that uses female social networks to disseminate new information in rural Uganda, which we refer to as the Social Network Intervention (SNI). We exogenously paired farmers in a networking session in which participants were taught new information. Each woman was paired with another randomly selected female cotton farmer who she did not already know. Both women were invited to the initial networking session in which information about better farming techniques was provided. The paired women were given pictures of each other (Polaroids) and asked to speak to each other throughout the cotton-growing season. 
In addition to comparing the SNI to the standard counterfactual (no intervention) we also compare the SNI with a standard extension training model similar to training previously implemented by extension agents in Uganda. ${ }^{1}$ In the standard training program, women and men were invited to attend a series of training sessions designed to impart the same information: both interventions focused on the same list of agricultural information points provided to our team by local ginners with the idea that these were simple, inexpensive and important techniques for improving cotton yields. ${ }^{2}$ Whereas participants in the SNI met once with our team and were asked to talk with each other after that point, the standard training (TR) disseminated information via biweekly visits from a trainer during the five critical stages of the season: pre-planting, planting, pesticide use, harvesting, and marketing. Due to the possible additive effects of social networking and training, we randomized the two programs across villages to also include a sample in which both the SNI and TR were implemented for the same people. We compared our results to a control group that did not receive any training.

We show that the SNI had a positive impact on overall outcomes. Difference in difference estimates of cotton yields show that cotton farmers in villages that received the SNI experienced large gains compared to the control group. A Tobit specification, which accounts for the fact that many farmers chose not to plant cotton in 2010, shows significant gains from SNI for all farmers including, independently, both men and women. Similarly, an OLS regression of yields shows gains for all but the highest performing farmers (namely, those with starting yields greater than 400 kilograms per hectare, where the average starting yield is 180 kilograms per hectare). In addition, we show that women paired in the SNI intervention were more likely to talk to each other after the intervention, that knowledge about farming (as measured by a test administered in the second round) was higher for women who received the intervention, and that pairing women with each other increased yields even for women who did not attend the information sessions. Finally, men, despite not being directly treated, also gained in yields.

Our intervention falls into the purview of network alteration interventions as summarized by Valente [2012], and this is one of few studies in the development literature that uses a randomized encouragement design aimed at exogenously changing social networks. ${ }^{3}$ Recent literature on

\footnotetext{
${ }^{1}$ See Baffes and Maratou-Kolias [2013] for details regarding the training program.

${ }^{2}$ See Appendix B for the list of information points.

${ }^{3}$ See Mullally et al. [2013] for an overview of randomized encouragement designs in agriculture.
} 
networks suggests that the structure of a network and the roles of individuals within that network can have important implications in learning [Bandiera and Rasul, 2006, Bramoullé et al., 2014, Bramoullè et al., 2009, Bursztyn et al., 2014, Conley and Udry, 2001, 2010, Jackson and Golub, 2012]. Perturbing the network structure is one method of understanding the mechanisms of learning, particularly when the reflection problem confounds network effects [Manski, 1993]. Field et al. [2013] is another recent study that exogenously perturbs new microfinance groups in Bangladeshi villages by varying the meeting frequency of these groups to understand the impact of network effects on loan repayment. BenYishay and Mobarak [2016] also examine information flows by perturbing village networks in Malawi. They study information diffusion by altering which member of the network received an incentive to spread information. They find that peer farmers in Malawi (average village members selected by a local focus group), when provided with a small incentive, are more effective at promoting adoption than lead farmers (leaders identified by the same community focus group), or government-employed extension workers.

Where our study, Field et al. [2013], and BenYishay and Mobarak [2016] attempt to alter the structure of the network, other studies, such as Adelman [2013], Leonard [2007], Duflo and Saez [2014] and Marmaros and Sacerdote [2002] use natural variation in networks to identify network effects. Still others use other sources of variation to understand when and how networks can affect decisions. For example, Breza [2016] uses natural variation in loan repayment incentives to study the impact of a peer's repayment on an individual's timing of payments, and shows evidence of network effects, and Banerjee et al. [2013] exploit the natural random variation found in the network centrality of each individual who was initially exposed to their microfinance program to identify network effects.

Where we differ from other research is in our focus on developing new network ties between females, specifically, between individuals who do not know each other well but who may have different sources of valuable information. These nascent and weaker connections may be more likely to propagate new information [Granovetter, 1974, 2005, Santos and Barrett, 2005] and may therefore be more useful to individuals (and the network as a whole) than expanding the raw size of the network. Weak ties may also better incorporate individuals who might otherwise not be reached by a central individual in a village, or may not be selected for extension training sessions. 
We believe that our findings have implications for developing more effective and more costeffective extension training programs. Extension agents are frequently spread thinly across hundreds of farmers, without the time or resources to address each farmer's concerns in their execution of new farming techniques. Furthermore, the more distant and less skilled farmers are often not selected for training programs, and may not even receive a second-hand account of a training session.

This paper is organized as follows: section 2 provides background on the research context and describes the data collection and randomization. In section 3 we examine the evidence for improved yields among our sample, focusing on our targeted farmers: women and farmers with lower yields. Having shown the strong positive impact of the program, we examine some potential channels through which the intervention may have affected outcomes. Section 4 concludes.

\section{Data}

Although it is likely that networks play important roles in all settings, measuring the value of a social network is easier when opportunities for learning are high and existing networks are incomplete. This study's focus in Uganda is an excellent setting to examine the role of social networks and learning in farming for a variety of reasons. First, farmers are growing a crop that was only recently reintroduced. Due to civil war and political unrest, cotton production ceased under Idi Amin's regime when the majority of the Indians who managed Uganda's businesses were persecuted and expelled. As a result, at least one generation passed in which no transfer of knowledge occurred for this cash crop. It is precisely in these circumstances, where technologies are nascent, that social networks and learning should have their greatest impacts.

Second, since the reintroduction of cotton, the government and ginners have tried to improve productivity using various extension services, but none of these education campaigns were targeted towards women. Baffes [2009] shows that male heads of households' crop yields are three to four times those of female heads of households in Uganda. As females supply 70-80\% of agricultural labor in rural Uganda and are responsible for up to $80 \%$ of food crop production [Tanzarn, 2005], low female crop yields are a tremendous loss to national welfare and have been a subject of significant research in Uganda and developing countries in general [Quisumbing, 2003, 
Udry, 1996, Udry and Goldstein, 2006].

Third, women who grow cotton undoubtedly belong to social networks, but the chances that their existing networks include optimal numbers of women cotton farmers are low. While males' days are delineated by morning work and afternoon discussion with other males, women's days are often a simultaneous combination of work, childcare, and household responsibilities. Women's wider range of household responsibilities raises the cost and reduces their availability for acquiring new production techniques. As such, existing female social networks develop primarily around household and childcare responsibilities, and these networks are not the best place for women to learn about cotton production. Further, female production networks will also be less oriented around cash crops than those of men [Edmeades et al., 2008, Katungi et al., 2008]. Responsibilities close to the home also restrict females from participating in geographically dispersed social networks and community projects, and force their relationships to be dependent on the collaborative tasks that they perform with other females, such as collecting water and fuel, and harvesting crops [Maluccio et al., 2003]. Thus, though there are significant opportunities provided by the government and ginners for farmers to learn about cotton growing, women, in particular, face numerous obstacles to attending such learning sessions and thereby improve their productivity and yields.

To investigate the role of networks in cotton farmers' productivity, we introduced two randomized interventions in cotton farming villages in the North and Northeast of Uganda. ${ }^{4} \mathrm{~A}$ household survey was administered in randomly selected villages in the two major cotton growing regions of Uganda: North (13 villages) and Northeast (13 villages). The baseline data were collected from February through May 2009. The second round was collected in March through May 2010. We interviewed randomly selected households that grew cotton in 2008 stratified by headship gender. ${ }^{5}$ The household survey consisted of questions on household demographics, input use and outputs for cotton and other crops grown, household controls of financial assets, including sales from cotton, and a separate survey instrument on farmers' social networks regarding adoption, cultivation, and marketing of cotton.

\footnotetext{
${ }^{4}$ This was part of the larger RCT that implemented a cotton training program under "Gender Dimension of Cotton Productivity in Uganda" led by Laoura Maratou (University of Maryland) and John Baffes (World Bank). For a basic overview of the interventions see Vasilaky [2013].

${ }^{5}$ The head of the household was defined as the individual who made land, resource and income allocation decisions in the household.
} 
In order to compare two different methods of transmitting the same information, we disseminated the same information about cotton growing through two different interventions, testing each separately as well as combining the two. To do this, we randomly assigned these treatments by village. By randomizing the SNI and TR programs across villages, we were able to measure the effects of the SNI treatment and the TR treatment, and the complementary effects of both treatments against a control group. The SNI was targeted to all female cotton farmers who were surveyed in SNI villages, and the TR was targeted to all surveyed farmers (men and women) in TR villages. We first randomly selected villages from a list of cotton growing villages in Oyam District and Mbale District. Among those villages, we randomly assigned SNI and TR treatments. A total of 13 villages received SNI, and 17 villages received TR. Table 1 represents the sample sizes across the two treatments. While only some villages were selected to receive one of the two programs, every village in our sample was visited by our team. Therefore, the effects from our results cannot be attributed purely to a behavioral response to our visits.

Finally, in each village we conducted a census of all female and male cotton growers. ${ }^{6}$ We then randomly selected 7 female and 7 male farmers to be surveyed in two crop years. Therefore, approximately an equal number of male heads and female heads of households participated in the study. In villages that received the TR intervention, all households selected for the survey were invited to training sessions conducted by a local agronomist for five training stages in 2009: pre-planting in March through April; planting in May; pesticide use in July through August; harvesting in October through November; and marketing in December and January. All farmers in the village were invited to the training sessions, and care was taken to make sure that female participation was encouraged and welcomed. We know from the logs of these sessions that women did attend, but not every invited farmer attended every session.

In villages that received the SNI, the 7 surveyed female farmers and an additional 7 female farmers were invited to one information training session. ${ }^{7}$ The intention was to incorporate a greater number of females in the study, beyond those who were surveyed, and increase the number of individuals participating in the game information sessions. This training consisted of teaching farmers precisely the same facts provided in the training session, and enumerated in

\footnotetext{
${ }^{6}$ All farmers on the census list were farmers who had harvested cotton in the previous season.

${ }^{7}$ Note that the 7 additional farmers were not surveyed in the larger study.
} 
the Appendix, but in a less repetitive fashion where the teaching was spread among all female participants. At the conclusion of the session, women were paired with another woman trained during the same session. The goal of these two stages was to add a new network link for each woman, and to increase the reach of the training information.

The pairing was achieved by first stratifying the cotton-growing participants into distinct geographic areas of the village, ${ }^{8}$ and then randomly pairing individuals within these areas. ${ }^{9}$ Following this initial pairing, we inquired if the pairs spoke to one another regarding cotton issues. ${ }^{10}$ We re-selected a pair if the individuals spoke to each other about production or if both were to receive training in training villages. Thus, in villages that received both the SNI and the training intervention, each pair consisted of at least one female who was invited to receive training and one female who was not invited to receive training. Each pair received a Polaroid photo of themselves and their partner, identified cultivation issues, chose a collaborative goal, and set potential times when they would meet to exchange information. They then presented this to their peers at the group information meeting. In this way, they were strongly encouraged to build a relationship to discuss cotton growing. Individual participants appeared to take the pairing exercise seriously, despite not being given any incentives to attend our meetings or to continue speaking with one another during the season.

To measure the impact of the intervention we look at unbiased estimates of the intentionto-treat (ITT), which includes cultivators as well as non-cultivators. ${ }^{11}$ We then investigate the treatment-on-the-treated (TOT), which includes cultivators only. Table 2 reports summary statistics of our farmers', including their average yield. The average Ugandan cotton farmer in our sample produces between 100 and 200 kilograms per year. ${ }^{12}$ Standard deviations for the yield

\footnotetext{
${ }^{8}$ This was to ensure that females were sufficiently distant from one another such that they most likely did not speak to one another on production issues, but also were not separated by large geographic constraints.

${ }^{9}$ We used numbers randomly drawn from a uniform distribution, $U[0, x]$, where $x$ represents the number of individuals in the group. We would then pair individual "1" with the first listed number on the list of numbers drawn from $\mathrm{U}[0,14]$. If the first number was " 1 " then we would select the next number in the list, perhaps " 3 ". Now " 1 " and " 3 " would be paired, " 3 " would be crossed out, and we would continue down the list in this way until all 14 women were paired.

${ }^{10}$ In only 2 instances did this occur, and we then re-paired individuals to ensure that all pairs had not spoken to one another about production issues.

${ }^{11}$ For the purposes of first estimating the ITT, Bulte et al. [2014, footnote 21] assign a zero yield to even those farmers who have not planted. Similar research also provides the ITT as a first step of estimating program impacts in randomized agricultural programs studying yield outcomes [BenYishay and Mobarak, 2016, Kondylis et al., 2014].

${ }^{12}$ One kilogram of seed cotton yields 0.30 kilograms of cotton lint-which could produce one to two t-shirts, for example - and return 30-40 US cents (600-900 shillings per kilogram) to a Ugandan farmer. Seed cotton refers to the harvested cotton lint and seed, where the seeds have not been filtered from the lint. Cotton seed refers to the actual
} 
of cotton (kilograms per acre) and level of cotton (total kilograms produced) are particularly high. The number of acres used to grow cotton is between one-half and one acre on average. Though land is not seen as scarce, the labor required to clear and prepare the land renders yield per acre a more accurate measure of productivity than total production. Also of note is that average output per kilogram of seed was 52 kilograms in 2009 and fell to 37 kilograms in 2010 . In 2010, both the Northern and Eastern parts of Uganda suffered from rain deficits in both treatment and control areas [Namara and Bitekerezo, 2010].

Before estimating the effects of the intervention, we also check that our treatment assignment is balanced. F-statistics in Table 3 show the joint test of whether the effects of treatment assignment are different from zero. We do observe some imbalance. We can see that for the overall sample age and education differ from the control at $10 \%$ significance. Table 4 shows the balance for females only. For females who received the SNI treatment we see that age is not imbalanced, while education and inputs, including used acreage and pesticides are not statistically different across all three treatment groups at $5 \%$ and $10 \%$ significance levels, respectively. A difference in difference framework will difference out any constant imbalances along observables, and we also confirm that our conclusions are largely unchanged after controlling for the latter variables in section 3 .

\section{Estimation}

Our intervention is motivated by the standard target-input learning model [Foster and Rosenzweig, 1995, Jovanovic and Nyarko, 1996], but with the understanding that weak network links might provide important information for growing cotton. In the standard version of the model, households can learn by doing (learning from their own experiences) as well as from the experiences of others in their community. The speed with which households learn will depend on the number of people from whom they can learn as well as the fidelity of the signals they observe. We consider the possibility that distant links, though suffering from reduced fidelity in transmission, might provide essential additional information because the signals are less likely to be correlated with the farmer's own signal. ${ }^{13}$ In other words, a farmer's immediate neighbor's plot

seeds that the cotton plant produces.

${ }^{13}$ See Appendix $\mathrm{C}$ for a formal exposition of the model. 
might provide a precise signal about the optimal level of inputs that is virtually identical to the farmer's own signal, and, is therefore, not very informative.

On the other hand, information from a more distant farmer may be less precise but provide more independent information. Take for example, a pest infestation. Farmers need to decide when to apply pesticides after observing pests: should they apply them at first sight of a pest, or wait to see if the infestation worsens? Since pest infestations spillover to neighboring farms, when a farmer observes yields following a timing choice, she needs to take into account the fact that her own yield depends on her neighbors' choices and that her neighbors' yields depend on her choice. Thus, she may collect precise but not independent signals. On the other hand, the choices and results from distant farmers may provide more information about optimal timing, because there are no spillovers.

This intervention was not directly designed to increase the size of a woman's network, but to improve the quality of learning in the network by adding (or improving) a different kind of link. We asked women to communicate more with another specific woman chosen from a different area of the village and with whom they did not previously exchange information about cotton farming. The pairing is easiest to understand as an increase in the fidelity for an existing link with greater independence of signals. This type of intervention is likely to be beneficial to women because women's networks have been shown to be geographically limited [Katungi et al., 2008]. Additionally, we have specifically chosen to test this implication in a setting where accumulated learning levels are low, women tend to have low quality production networks to begin with, and low levels of education and previous extension outreach suggest that the precision of initial guesses about timing are low.

Importantly, we can verify that the pairings we encouraged were between farmers who did not previously observe one other's input decisions. We look at whether individuals in the SNI intervention mentioned the person to whom they were assigned in the social network survey. First, we ensure that no participants mentioned speaking to their pair in the 2009 baseline survey, confirming our strategy of forming new, weak network links with the pairings. Examining the list of new names added in 2010, we find that $26 \%$ of our SNI participants specifically mentioned their pair, suggesting that the SNI pairings did create new links. ${ }^{14}$

\footnotetext{
${ }^{14}$ Women in the control villages added, on average, two and a half new names to their rosters in the second year.
} 
We test these hypotheses using the following reduced form regression:

$$
\begin{aligned}
q_{t}(S N, T R)= & \alpha_{0}+\alpha_{1} S N I+\alpha_{2} T R+\alpha_{3} S N I \cdot T R+\beta_{0} \cdot t \\
& +\beta_{1} S N I \cdot t+\beta_{2} T R \cdot t+\beta_{3} S N I \cdot T R \cdot t+u
\end{aligned}
$$

The estimated $\hat{\beta}_{1}$ captures the average treatment effect (ATE) of the SNI on yields, namely the effect of SNI across time, or $S N I \cdot t$ where:

$$
\begin{aligned}
& \hat{\beta}_{1}=[E(y \mid S N I=1, t=1, T R=0)-E(y \mid S N I=1, t=0, T R=0)]- \\
& {[E(q \mid S N I=0, t=1, T R=0)-E(q \mid S N I=0, t=0, T R=0)]}
\end{aligned}
$$

$\hat{\beta}_{2}$ captures the effect of TR on yields and $\hat{\beta}_{3}$ captures the effect of the combined programs as separate from the summed effects (across time). We expect both $\beta_{1}$ and $\beta_{2}$ to be greater than 0 .

We measure the impact of the SNI both by looking at the overall gain in yields for women and men and looking at the degree to which the intervention encouraged women to continue planting cotton. ${ }^{15}$

\subsection{Cotton Yields}

We first estimate the reduced form effect of SNI and TR on cotton yields (Equation 2) in a difference in difference framework. Yields are defined as the total output divided by intended acreage. An ordinary least squares approach provides unbiased and interpretable estimates of the intent to treat. The outcome variable, yield, represents the kilograms of cotton seed output per acre. ${ }^{16}$ We are interested in the coefficients on $S N I \cdot t$, and $S N I \cdot T R \cdot t$ : that is, the pure impact of the SNI on outcomes, and the interaction effect of SNI and TR. Note that we also check that the estimated coefficients on $S N I, T R$ and $S N I \cdot T R$ are insignificant, demonstrating the

However, given that an average of 96 individual names were mentioned across all surveys within a village, there is only a $3 \%$ probability of selecting one individual name in a random process with two and a half draws out of sample of 96 . Thus, the finding that $26 \%$ of households mentioned their pair is notably different from what we would expect from a random process.

${ }^{15} \mathrm{In}$ all of the regressions below, standard errors are clustered at the village level, as well as using a cluster wild bootstrap in Appendix A [Cameron et al., 2008, 2011].

${ }^{16}$ Table 13 presents the main estimates using wild bootstrapped standard errors, and Table 14 presents the main results using a panel structure with fixed effects. Neither change the interpretation of our results. 
validity of the random selection. Similarly, the $t$ variable measures whether there is a significant time trend in yields, which we expect to be negative given the adverse weather events (drought) in 2010. The estimated impacts of $S N I \cdot t$ and of $S N I \cdot T R \cdot t$ on total yield (Column 1) are insignificant. The impact of receiving both the SNI and TR is the sum total of $\beta_{1}, \beta_{2}$, and $\beta_{3}$. $\beta_{3}$ is not statistically different from zero suggesting that the effects are not substitutes, which is likely if the two interventions are effective for different groups.

Yields in this sample are right skewed and most producers, before and after the treatments, produce less than 400 kilograms per acre. According to standard models of learning, we should not expect a significant impact from SNI or TR for those who are already productive because of previous learning. Column 2 of Table 5 estimates Equation 2, conditional on having grown 400 kilograms of cotton per acre or less in 2009 (which excludes the top 11\% of our original sample). Columns 3 and 4 show the same sample divided into male- and female-headed households. ${ }^{17}$

The SNI treatment has a positive and significant impact on households who harvested less than 400 kilograms of cotton in 2009 as shown in Column 2. On average, females in the SNI treatment gained a total of 98 kilograms per acre (Column 3), while men living in SNI villages gained 70 kilograms per acre (Column 4), conditional on their starting yields. The effects of the training program are comparable at 72 kilograms per acre for females (and this effect is not statistically different from the average SNI effect, $\mathrm{p}$ value $=0.7)$. Considering that the average yield across 2009 and 2010 was 160 kilograms per acre, the gains from SNI are economically significant for both men and women. The interaction effect between SNI and TR is negative (though not significant), indicating that the joint effect of the SNI and TR is less than the sum of each intervention's independent effect. This is not surprising given that SNI and TR introduce the same information, but using different dissemination methodologies. Note that, because 2010 was a bad year compared to 2009, most of the gains we observe from the two interventions are actually avoided losses, rather than net gains.

We next estimate a Tobit model to account for the underlying right skewed distribution,

\footnotetext{
${ }^{17}$ Note that despite the SNI being a randomly assigned program, in 2009, women who were selected for the SNI happened to be worse off than those who were not. It is not surprising that, as we continue to subdivide our sample (in this case, women with less than $400 \mathrm{~kg}$ production in the first period), we will find small groups that are not balanced - this result does not mean that the randomization is invalid. Importantly, however, this baseline difference is controlled for by using a difference-in-difference framework in Table 12 and Table 11, and does not change our main results.
} 
where a zero is considered the result of a latent process which is itself driven by our treatments. Table 5 exhibits the results in Columns 5-8. The results are significant and larger than the OLS estimates in Columns 1-4, and provide additional support that the SNI had a positive effect on farmers' outcomes. ${ }^{18}$

Finally, we also look at the effect of the intervention on inputs in Table $6{ }^{19}$ Inputs for the overall sample did not change for this period, including for females alone. Seed, land and pesticide use remained constant while yields increased, suggesting that practices beyond inputs increased yields for females.

\subsection{Growing and Harvesting Cotton}

As noted earlier, the respondents in our sample experienced a drought in 2010. Almost everyone's yields declined between 2009 and 2010, as noted by the Table 2. A number of farmers experienced zero yields, and both the SNI and TR prevented overall declines as compared to the control group. In 2009, within our full sample of male and females farmers, 6 households experienced no output. By 2010, 136 households experience zero yields - 90 of them did not plant, and 46 grew, but had zero yields.

One possible impact of the intervention is that it encouraged farmers to continue planting cotton. To test this, we look at the impact of the SNI and TR on farmers' decisions to grow cotton. Table 7 estimates the effect of the SNI and TR on remaining a cotton grower between 2009 and 2010, despite the adverse weather shocks mentioned earlier. We use a probit model to predict the probability that a grower continues to grow cotton where the outcome variable is 0 if the individual ceased to grow cotton in 2010, and equals 1 if they planted cotton. Column 1 indicates that the presence of the SNI in a village positively and significantly impacted a farmer's decision to continue to grow cotton. The marginal effect of the program at mean values is an $18 \%$ increase in the probability of remaining a cotton grower. Training a farmer increased the probability of remaining a cotton grower by $11 \%$ but is statistically insignificant. For females, the increase is greater, where the SNI increased the probability of remaining a cotton grower by $38 \%$ and $25 \%$ for training. Although we cannot reject the hypothesis that TR and SNI have the

\footnotetext{
${ }^{18}$ In this specification females experienced a smaller increase in yields relative males, but the difference is not statistically significant ( $\mathrm{p}$ value $=0.36$ ).

${ }^{19}$ Table 15 presents the same estimates using wild bootstrapped standard errors.
} 
same impact, we can reject the hypothesis that female farmers in SNI villages are as likely to plant as female farmers in control villages.

Since both training and the social network intervention increased the probability that a woman would grow cotton in the subsequent year a natural next step is to evaluate whether yields improved conditional on cultivation. That is, conditional on growing cotton, did women in TR or SNI villages exhibit lower or higher yields than women in control villages? Conversely, it is possible that not only did the treatments encourage women to grow cotton, but they also made them better cultivators than those farmers in control villages who continued to grow (and may be likely to have been among the better farmers). To test the similarity of the distributions across treatments for those who planted cotton in 2010, in Table 8 we use a probit to look at the effect of SNI on the probability of a positive harvest in 2010 restricting the sample to only those farmers who chose to grow cotton in 2010. In Column 1, we see that in this sample, the SNI has a significant effect for the overall sample and for men alone. However, when we reduce the sample to females who had yields less than 400 in the baseline, the effects, though positive, are not significant.

Examining the case of women who had yields below $400 \mathrm{~kg}$ per acre in 2009, we learn about the relative size of the intensive and extensive margin effects. Women who received only the SNI treatment were 38.5 percentage points more likely to plant cotton than women in control villages. Since the average yield for all such women who planted cotton in 2010 was $147 \mathrm{~kg}$ per acre, this would suggest that examining only the extensive margin, SNI should have increased the average yield by $0.38^{*} 147$ or $57 \mathrm{~kg}$ per acre. Comparing this to the estimated coefficient of $98 \mathrm{~kg}$ per acre (see Table 5), the intensive margin would be about $41 \mathrm{~kg}$ per acre. However, $98 \mathrm{~kg}$ per acre is not statistically different from $57 \mathrm{~kg}$ per acre, so the estimate of the intensive margin is not significantly different from zero.

If we consider women who received SNI and also received training, we find they are about 43 percentage points more likely to plant and experience a gain of about $120 \mathrm{~kg} /$ acre (based on the estimated coefficient). Again, using the overall average of $147 \mathrm{~kg} /$ acre, the extensive margin implies a gain of about $63 \mathrm{~kg}$ per acre leaving an intensive margin of about $57 \mathrm{~kg}$ per acre. Thus, having been encouraged by the interventions to plant cotton, women in these villages gained somewhere between 57 and $63 \mathrm{~kg}$ per acre, and being better farmers led to imprecisely estimated 
gains of between 41 and $57 \mathrm{~kg}$ per acre. However, we cannot draw any definitive conclusions from this estimate alone, given its self-selected sample.

Thus, for this subsample, the SNI increased the probability that treated women would choose to plant cotton and increased the probability that men who did plant would have a positive yield. In addition, the evidence suggests that women who did plant because of the SNI intervention did not experience worse outcomes than women who chose to plant in the control villages. Note that since the decision not to plant is endogenous, we cannot make an identified causal conclusion about the actions of this sample, however, overall, this estimation suggests that the bulk of the impact for women is on the extensive margin - the decision to plant - and the impact for men (despite not directly receiving the treatment) is on the intensive margin - the probability that they would have a positive harvest conditional on choosing to plant.

\subsection{Intervention Costs}

The SNI had a significant and positive impact - impacts that are not statistically different from a standard extension training program. However, the social network intervention is significantly less expensive than the standard extension training intervention. Typical extension training programs are costly. Each trainer can only train a handful of farmers at any one time before quality and reach degrade. In addition, it takes man-hours, transportation and fuel to reach remote villages.

Thus, one of the primary benefits of the social network intervention is that it required only two visits from a lead extension trainer with an assistant for each village, whereas the training intervention required nine visits per village. The overall cost of the traditional training program was $\$ 7,080$ USD with each extension trainer leading anywhere from 7-30 farmers each at a given demonstration on a bi-weekly basis for an approximate cost of $\$ 20$ USD per farmer for 354 trained farmers. In comparison, the SNI costed $\$ 2,080$ for approximately the same number of farmers - $30 \%$ of the cost and a little more than $\$ 5$ per farmer. Conversely, the overall benefit per acre to a female farmer, assuming a return of $\$ 0.30$ per kilogram of seed cotton, ${ }^{20}$ and the estimated effect sizes from Table 5, was $\$ 29$ per acre for the SNI and $\$ 21$ per acre for the TR. For the

\footnotetext{
${ }^{20}$ The Cotton Development Organization announces indicative prices for seed cotton each year. In 2009 and 2010 , the indicative price was 900 Ugandan Shillings [Ahmed and Ojangole, 2012].
} 
average female farmer with little over half an acre, the SNI remains a cost effective investment, while the training does not. Note that this analysis assumes no spillovers despite the evidence that the SNI, in particular, benefitted untreated men as well as treated women.

\subsection{Testing the Impact on Knowledge}

It is helpful to understand if the intervention improved outcomes through knowledge acquisition at the information meetings, or potentially through other informal learning outside these meetings. To investiage whether the gains in yields came from the increased knowledge that women acquired during the meetings, we examine women's scores on a quiz of cotton-farming knowledge. As part of the survey in the second round, we gave each farmer a quiz on the information taught in the initial meetings for the SNI. We then calculated the percentage of correct answers to the 12 questions on the information points taught (see Appendix B). This data can only be analyzed in a cross-sectional regression, taking advantage of the randomization to identify program impacts. As a check on our cross-sectional results, we also examined the yield regressions in the same framework. Given that the assignment of programs is random, the impact of SNI and TR should not be statistically different whether we use panel or cross-sectional data for the full sample.

Table 9 shows that both the SNI and TR improved the scores of participants by between $4 \%$ and $5 \%$, or about half a question. Given that the initial average score was about $40 \%(4.5$ questions correct out of 12), this is not an unimportant improvement. However, it is clearly not the case that farmers remembered everything that they learned in either the information session or the training. Using quiz scores over the whole sample from 2010, we estimate that farmers who scored $10 \%$ higher on the test experienced 27 kilograms per acre greater yields (30 kilograms for a restricted sample of women). This suggests that an increase of $5 \%$ on the test would increase yields by around 15 kilograms per acre. In comparison, we estimate that female yields increased by between 60 and 90 kilograms, suggesting that improved knowledge is directly responsible for only a small proportion of the gains.

In addition, there is a subset of females who participated in the pairing meetings and the social network survey who were unable to attend the initial information games. These individuals were paired but did not directly receive or learn the information taught via the games. Therefore, we created another treatment variable, information, which assumes a value of 1 if an individual 
attended the meetings and was paired, and assumes a value of 0 if the individual did not attend the meetings, but was paired with a new link in the second round. If $S N I \cdot t$ is insignificant after controlling for information, then we might conclude that the program's effect is operating via the information games and not through the pairings. Of course, attendance in the information meetings was voluntary, and therefore, information is endogenous. Women who attended may have had lower opportunity cost or greater expected benefit from attending.

Table 10 includes the estimates of the information variable in the panel model for females. In the OLS specification Information is not a significant contributor to the gains in female yields while SNI remains significant. This would suggest that attending the information sessions alone was not the only mechanism by which the SNI improved yields for females. Of course, this effect may be muted if better farmers experienced less of an improvement on average. Note that those who attended the meetings were, on average, better farmers before the intervention than those who missed the meeting. Taken together, the results on quiz scores and attendance suggest that the meetings may have improved quiz scores, but that this additional knowledge explains only about $20 \%$ to $25 \%$ of the gains observed under the treatment.

\section{Conclusion}

Our research estimates the effects of a social network-based agricultural training program in which female cotton farmers were given new information and encouraged to form paired links with other female cotton farmers with whom they had not previously interacted. Our estimated impacts of the SNI are positive and significant for farmers who were producing up to 400 kilograms per acre in 2009, where the average Ugandan farmer produces between 100 and 200 kilograms per acre per year. In particular, the difference in difference estimates of SNI on yields show that pairing female cotton growers with someone they do not know, as well as providing pairs with new knowledge to share, increased yields by 98 kilograms per acre on average for females. Furthermore, while the SNI had its greatest impact on females' yields, it also had positive spillover effects for males. This simple intervention achieves results that are similar to those achieved with more conventional methods of transmitting information, with benefits to those who are not directly targeted. 
Several mechanisms may have contributed to the effectiveness of the SNI; however, future research is necessary to determine the specific mechanisms at play. We consider the direct effects of the intervention-new links and new knowledge. The evidence suggests that the encouragement of new links with other farmers was successful; we saw an increase in the number of new relationships discussing cotton production issues, particularly between women who were exogenously paired. On the intensive margin, productivity increased overall, and for males alone. However, estimates are less precise for females. The fact that men were never encouraged to form new links but increased their yields suggests that improvements in knowledge within their existing networks could have helped. For women, we find that the SNI expanded participants' agricultural knowledge (as seen on tests), and these gains can account for about $20 \%$ of the increase in farmers' yields. It is likely that the majority of improvements for females came from the pairing of females to other women who had new sources of information. This may have encouraged female farmers to grow the cash crop, but also enabled them to perform as well as their average peer, even during a difficult year.

Taken together, our research shows that there are large gains from a development approach that encourages the use of social networks in the presence of new information to improve yields for female farmers. With our approach, low-cost agricultural training is possible without a topdown training structure, and it can be more effective at improving outcomes for the poorest farmers, who are very often females. This research is particularly relevant for extension services in Uganda, the National Agricultural Advisory Services (NAADS), which is becoming more decentralized, encouraging multiple providers and methodologies for extension services, with the aim to address the specific inequalities present at a village level [Kahubire, 2005, Lungahi and Opira, 2013]. NAADS has already moved away from direct visitation to group based visits, mainly because direct visitation was not found to have a significant impact on outcomes [Benin et al., 2011]. Further, NAADS has implicitly focused on larger male-headed households. As such, our approach provides a tested methodology for incorporating a very decentralized process into extension services. As women are effectively excluded from higher quality agricultural networks and have fewer opportunities to learn about better farming practices, this method can help overcome this training gap. Further, the SNI program also has positive impact for males as well.

These results point to a number of directions for future work, including developing a greater 
understanding of whether new, weak network connections facilitate information exchange, whether information transmission via such connections is sustainable, and whether this methodology extends to other domains such as the adoption of health practices or information communication technologies. 


\section{References}

Sarah Adelman. Keep your friends close: The effect of local social networks on child human capital outcomes. Journal of Development Economics, 103(0):284 - 298, 2013.

M. Ahmed and S. Ojangole. Analysis of incentives and disincentives for cotton in uganda. Food and Agriculture Organization of the United Nations, Technical notes series, page 16, 2012.

J.R. Anderson and G. Feder. Agricultural extension. In R. Evenson and P. Pingali, editors, Handbook of Agricultural Economics, volume 3, page 2346. Elsevier, 2007.

Solomon Asfaw, Menale Kassie, Franklin Simtowe, and Leslie Lipper. Poverty reduction effects of agricultural technology: A micro-evidence from tanzania. Food and Agricultural Organization of the United Nations, Agricultural Development Economics Division, Working Paper, 2011.

John Baffes. The 'full potential' of uganda's cotton industry. Development Policy Review, 27(1): $67-85,2009$.

John Baffes and L. Maratou-Kolias. The Gender Dimension of Uganda's Cotton Sector. The World Bank, Washington DC, 2013.

Oriana Bandiera and Imran Rasul. Social networks and technology adoption in northern mozambique. The Economic Journal, 116(514):869-902, 2006.

Abhijit Banerjee, Arun Chandrasekhar, Esther Duflo, and Mathew Ojackson. Diffusion of microfinance. Science, 341, 2013.

Samuel Benin, Ephraim Nkonya, Geresom Okecho, Jose Randriamamonjy, Edward Kato, Geofrey Lubadde, Miriam Kyotalimye, and Francis Byekwaso. Returns to spending on agricultural extension: the case of the national agricultural advisory services (naads) program of uganda. Agricultural Economics, 42(2):249-267, 2011.

Ariel BenYishay and A. Mushfiq Mobarak. Social learning and incentives for experimentation and communication. Review of Economic Studies, Conditionally Accepted, 2016.

Yann Bramoullé, Rachel Kranton, and Martin D'Amours. Strategic interaction and networks. American Economic Review, 104(3):898-930, 2014. 
Yann Bramoullè, Habiba Djebbari, and Bernard Fortin. Identification of peer effects through social networks. Journal of Econometrics, 150(1):41-55, 2009.

Emily Breza. Peer effects and loan repayment: Evidence from the krishna default crisis. Working Paper, 2016.

Erwin Bulte, Gonne Beekman, Salvatore Di Falco, Joseph Hella, and Pan Lei. Behavioral responses and the impact of new agricultural technologies: Evidence from a double-blind field experiment in tanzania. American Journal of Agricultural Economics, 96(3):813-830, 2014.

Leonardo Bursztyn, Florian Ederer, Bruno Ferman, and Noam Yuchtman. Understanding mechanisms underlying peer effects: Evidence from a field experiment on financial decisions. Econometrica, 82(4):1273-1301, 2014.

A. Colin Cameron, Jonah B. Gelbach, and Douglas L. Miller. Bootstrap-based improvements for inference with clustered errors. The Review of Economics and Statistics, 90(3):414-427, 2008.

A. Colin Cameron, Jonah B. Gelbach, and Douglas L. Miller. Robust inference with multi-way clustering. Journal of Business and Economic Statistics, 29(2):238-249, 2011.

Tim Conley and Christopher Udry. Social learning through networks: The adoption of new agricultural technologies in ghana. American Journal of Agricultural Economics, 83:668-732, 2001.

Timothy Conley and Christopher Udry. Learning about a new technology: Pineapple in ghana. American Economics Review, 100(1):35-69, 2010.

Esther Duflo and Emmanuel Saez. The role of information and social interactions in retirement plan decisions: Evidence from a randomized experiment. The Quarterly Journal of Economics, 118(3):815-842, 2014.

Svetlana Edmeades, Enid Katungi, and Melinda Smale. Gender, social capital and information exchange in rural uganda. Journal of International Development, 20(1):35-52, 2008. 
G. Feder, R. Murgai, and J.B. Quizon. The acquisition and diffusion of knowledge: The case of pest management training in farmer field schools, indonesia. Journal of Agricultural Economics, 55:217-239, 2004.

Erica Field, Benjamin Feigenberg, and Rohini Pande. The economic returns to social interaction: Experimental evidence from microfinance. Review of Economic Studies, 80(4):1459-1483, 2013.

Andrew Foster and Mark Rosenzweig. Learning by doing and learning from others: Human capital and technical change in agriculture. Journal of Political Economy, 103(6):1176-1209, 1995.

Mark Granovetter. The strength of weak ties. American Journal Sociology, 78(1):1360-1380, 1974.

Mark Granovetter. The impact of social structure on economic outcomes. Journal of Economic Perspectives, 19(1):33-50, 2005.

Carolyn R. Harper and David Zilberman. Pest externalities from agricultural inputs. American Journal of Agricultural Economics, 71(3):692-702, 1989.

Lan Anh Hoang, Jean-Christophe Castella1, and Paul Novosad. Social networks and information access: Implications for agricultural extension in a rice farming community in northern vietnam. Journal Agriculture and Human Values, 23(4):1572-8366, 2006.

Jonathan Isham. The effects of social capital on technology adoption: Evidence from rural tanzania. Journal of African Economies, 11(1):39-60, 2002.

Mathew O Jackson and Benjamin Golub. Does homophily predict consensus times, testing a model of network structure via a dynamic process. Review of Network Economics, 11(978-14503-1229-5):1-31, 2012.

Boyan Jovanovic and Yaw Nyarko. Learning by doing and the choice of technology. Econometrica, 64(6):1299-1310, 1996.

Edith Birungi Kahubire. The Delivery of Agricultural Extension Services in Uganda: An Analysis from an Institutional Perspective. PhD thesis, University of Oslo, 2005. 
Enid Katungi, Svetlana Edmeades, and Melinda Smale. Gender, social capital and information exchange in rural uganda. Journal of International Development, 20(1):35-52, 2008.

Florence Kondylis, Valerie Mueller, and Siyao Zhu. Seeing is believing? evidence from an extension network experiment. World Bank Working Paper, (7000), 2014.

D.K. Leonard. Reaching the Peasant Farmer: Organization Theory and Practice in Kenya. University of Chicago Press, Chicago, 1977.

Kenneth Leonard. Learning in health care: Evidence of learning about clinician quality in tanzania. Economic Development and Cultural Change, 55:531-555, 2007.

Esther Lungahi and John Opira. Agriculture extension in uganda. Baobab Magazine, 68:11, 2013.

J.A. Maluccio, L. Haddad, and J. May. Social capital and gender in south africa. In A Quisumbing, editor, In Household Decisions, Gender and Development, A Synthesis of Recent Research. International Food Policy Research Institute, Washington DC, 2003.

Charles Manski. Identification of endogenous social effects: The reflection problem. The Review of Economic Studies, 60(1):531-542, 1993.

David Marmaros and Bruce Sacerdote. Peer and social networks in job search. European Economic Review, 46:870-879, 2002.

Conner Mullally, Steve Boucher, and Michael Carter. Encouraging development: Randomize encouragement designs in agriculture. American Journal of Agricultural Economics, 95(5): $13521358,2013$.

Kavan Munshi. Social learning in a heterogenous population: Technology diffusion in the indian green revolution. Journal of Development Economics, 73:185-213, 2004.

Suleiman Namara and Mary Bitekerezo. The 2010-2011 Integrated Rainfall Variability Impacts, Needs Assessment and Drought Risk Management Strategy. Technical report, Office of the Prime Minister, Uganda, 2010. 
Agnes Quisumbing. Social capital, legal institutions, and property rights: Overview. In Agnes Quisumbing, editor, Household Decisions, Gender and Development, pages 139-144. International Food and Policy Research Institute, Washington DC, 2003.

Uri Regev, Andrew P. Gutierrez, and Gershon Feder. Pests as a common property resource: A case study of alfalfa weevil control. American Journal of Agricultural Economics, 58(2): 186-197, 1976.

Paulo Santos and Christopher Barrett. Interest and identity in network formation:who do smallholders seek out for information in rural ghana? Unpublished, Cornell University, 2005.

B.P. Sinha and P. Mehta. Farmer's need for achievement and change-proneness in acquisition of information from a farm-telecast. Rural Sociology, 37(3), 1972.

Nite Tanzarn. Revisiting the past, reflections on the future: Gender in science, technology and agricultural development. In Nite Tanzarn, editor, Gender in Agriculture and Technology, pages xvii-xxxii. Women and Gender Studies, Kampala, Uganda, 2005.

Colin Thirtle, Xavier Irz, Lin Lin, Victoria McKenzie-Hill, and Steve Wiggins. Relationship between changes in agricultural productivity and the incidence of poverty in developing countries. Technical report, DFID Report No.7946 27/02/2001, Feburary 2001.

Christopher Udry. Gender, agricultural production,and the theory of the household. Journal of Political Economy, 104(5):1010-1046, 1996.

Christopher Udry and Markus Goldstein. Addressing unequal economic opportunities, a case study of land tenure in ghana. Development Outreach, 8(1):7-9, 2006.

T. W. Valente. Network Interventions. Science, 337(6090):49-53, 2012.

Kathryn Vasilaky. Female social networks and farmer training: Can randomized information exchange improve outcomes? American Journal of Agricultural Economics, 95(2):376-383, 2013. 
Table 1: Treatment Sample Size (No. of Villages in Parentheses)

\begin{tabular}{lccc}
\hline & $(1)$ & $(2)$ & $(3)$ \\
& TR & No TR & Totals \\
\hline SNI & 96 & 59 & 155 \\
& $(8)$ & $(5)$ & $(13)$ \\
No SNI & 120 & 50 & 170 \\
& $(9)$ & $(5)$ & $(14)$ \\
\hline Totals & 216 & 109 & 325 \\
& $(17)$ & $(10)$ & $(27)$ \\
\hline
\end{tabular}


Table 2: Means of Main Variables in 2009 \& 2010

\begin{tabular}{lccc}
\hline & $(1)$ & $(2)$ & $(3)$ \\
& 2009 & 2010 & Average 2009 \& 2010 \\
\hline Social Network & 0.48 & 0.48 & 0.48 \\
Intervention (SNI) & $(0.500)$ & $(0.500)$ & $(0.500)$ \\
Training & 0.66 & 0.66 & 0.66 \\
Intervention (TR) & $(0.474)$ & $(0.475)$ & $(0.474)$ \\
Gender (Fem=1) & 0.48 & 0.48 & 0.48 \\
& $(0.50)$ & $(0.50)$ & $(0.50)$ \\
Education (Yrs) & 5.6 & 5.9 & 5.7 \\
& $(2.9)$ & $(2.9)$ & $(2.9)$ \\
Kg Cotton & 140.8 & 79.54 & 109.9 \\
& $(201.5)$ & $(129.2)$ & $(171.6)$ \\
Acres & 0.983 & 0.586 & 0.783 \\
& $(0.701)$ & $(0.593)$ & $(0.678)$ \\
Yield (Kg/Acre) & 182.0 & 139.5 & 160.6 \\
& $(208.7)$ & $(234.9)$ & $(223.1)$ \\
Kg Seed & 4.976 & 3.232 & 4.097 \\
& $(3.799)$ & $(3.000)$ & $(3.527)$ \\
Yield Per & 52.83 & 36.96 & 44.83 \\
Seed & $(78.32)$ & $(62.70)$ & $(71.27)$ \\
\hline Mean of each variable with standard & & \\
& &
\end{tabular}

Mean of each variable with standard deviation in parentheses. 
Table 3: Balanced Panel Checks

\begin{tabular}{|c|c|c|c|c|c|c|c|}
\hline VARIABLES & $\begin{array}{c}(1) \\
\text { fertilizer }\end{array}$ & $\begin{array}{l}(2) \\
\text { age }\end{array}$ & $\begin{array}{c}(3) \\
\text { education }\end{array}$ & $\begin{array}{l}(4) \\
\text { yield }\end{array}$ & $\begin{array}{c}(5) \\
\text { used acreage }\end{array}$ & $\begin{array}{c}(6) \\
\text { pesticide }\end{array}$ & $\begin{array}{l}(7) \\
\text { seed }\end{array}$ \\
\hline SNI & $\begin{array}{c}0.159 \\
(0.548)\end{array}$ & $\begin{array}{c}1.756 \\
(0.460)\end{array}$ & $\begin{array}{c}1.133 \\
(0.115)\end{array}$ & $\begin{array}{c}58.85 \\
(0.129)\end{array}$ & $\begin{array}{l}-0.355 \\
(0.101)\end{array}$ & $\begin{array}{c}-0.0165 \\
(0.939)\end{array}$ & $\begin{array}{c}0.198 \\
(0.841)\end{array}$ \\
\hline TRAINING & $\begin{array}{r}-0.0820 \\
(0.343)\end{array}$ & $\begin{array}{c}0.325 \\
(0.896)\end{array}$ & $\begin{array}{c}0.327 \\
(0.638)\end{array}$ & $\begin{array}{c}26.98 \\
(0.462)\end{array}$ & $\begin{array}{l}-0.260 \\
(0.203)\end{array}$ & $\begin{array}{c}1.583 \\
(0.336)\end{array}$ & $\begin{array}{l}-0.253 \\
(0.742)\end{array}$ \\
\hline $\operatorname{Tr} \cdot \mathrm{SNI}$ & $\begin{array}{l}-0.177 \\
(0.505)\end{array}$ & $\begin{array}{l}-5.066 \\
(0.113)\end{array}$ & $\begin{array}{l}-1.825^{*} \\
(0.0503)\end{array}$ & $\begin{array}{l}-15.22 \\
(0.800)\end{array}$ & $\begin{array}{c}0.270 \\
(0.279)\end{array}$ & $\begin{array}{l}-1.825 \\
(0.271)\end{array}$ & $\begin{array}{l}-1.226 \\
(0.312)\end{array}$ \\
\hline Constant & $\begin{array}{l}0.100 \\
(0.242)\end{array}$ & $\begin{array}{l}47.60^{* * *} \\
(0.0001)\end{array}$ & $\begin{array}{c}4.240^{* * *} \\
(1.56 \mathrm{e}-08)\end{array}$ & $\begin{array}{c}140.2^{* * *} \\
(1.61 \mathrm{e}-07)\end{array}$ & $\begin{array}{l}1.231^{* * *} \\
(3.54 \mathrm{e}-07)\end{array}$ & $\begin{array}{c}0.285^{*} \\
(0.0731)\end{array}$ & $\begin{array}{l}5.410^{* * *} \\
(9.54 \mathrm{e}-10)\end{array}$ \\
\hline Observations & 320 & 325 & 325 & 321 & 325 & 320 & 320 \\
\hline R-squared & 0.011 & 0.017 & 0.022 & 0.015 & 0.029 & 0.006 & 0.023 \\
\hline$F$ test $p$ value & 0.312 & 0.0613 & 0.0894 & 0.243 & 0.354 & 0.108 & 0.232 \\
\hline
\end{tabular}

p-values in parentheses, standard errors clustered at village level output and inputs in kgs per acre, education is years completed ${ }^{* * *} \mathrm{p}<0.01,{ }^{* *} \mathrm{p}<0.05,{ }^{*} \mathrm{p}<0.1$ 
Table 4: Balanced Panel Checks: Females

\begin{tabular}{|c|c|c|c|c|c|c|c|}
\hline VARIABLES & $\begin{array}{c}(1) \\
\text { fertilizer }\end{array}$ & $\begin{array}{l}(2) \\
\text { age }\end{array}$ & $\begin{array}{c}(3) \\
\text { education }\end{array}$ & $\begin{array}{c}(4) \\
\text { yield }\end{array}$ & $\begin{array}{c}(5) \\
\text { used acreage }\end{array}$ & $\begin{array}{c}(6) \\
\text { pesticide }\end{array}$ & $\begin{array}{c}(7) \\
\text { seed }\end{array}$ \\
\hline SNI & $\begin{array}{c}0.577 \\
(0.259)\end{array}$ & $\begin{array}{c}3.630 \\
(0.333)\end{array}$ & $\begin{array}{l}1.759^{* * *} \\
(0.00347)\end{array}$ & $\begin{array}{c}8.496 \\
(0.830)\end{array}$ & $\begin{array}{c}0.145 \\
(0.223)\end{array}$ & $\begin{array}{c}0.297 \\
(0.213)\end{array}$ & $\begin{array}{c}1.033 \\
(0.338)\end{array}$ \\
\hline TRAINING & $\begin{array}{c}0.00 \\
(0.0983)\end{array}$ & $\begin{array}{c}1.182 \\
(0.623)\end{array}$ & $\begin{array}{l}1.833^{* *} \\
(0.0130)\end{array}$ & $\begin{array}{c}44.92 \\
(0.273)\end{array}$ & $\begin{array}{l}0.270^{* *} \\
(0.0122)\end{array}$ & $\begin{array}{c}0.0878^{* * *} \\
(0.00321)\end{array}$ & $\begin{array}{c}1.013 \\
(0.220)\end{array}$ \\
\hline $\operatorname{Tr} \cdot \mathrm{SNI}$ & $\begin{array}{l}-0.577 \\
(0.259)\end{array}$ & $\begin{array}{l}-6.427 \\
(0.170)\end{array}$ & $\begin{array}{c}-2.843^{* *} \\
(0.0107)\end{array}$ & $\begin{array}{c}2.114 \\
(0.974)\end{array}$ & $\begin{array}{l}-0.331^{*} \\
(0.0506)\end{array}$ & $\begin{array}{l}-0.366 \\
(0.131)\end{array}$ & $\begin{array}{l}-2.017 \\
(0.118)\end{array}$ \\
\hline Constant & $\begin{array}{c}0.00 \\
(0.112)\end{array}$ & $\begin{array}{c}49.00^{* * *} \\
(0.00)\end{array}$ & $\begin{array}{c}1.500^{* * *} \\
(2.34 \mathrm{e}-05)\end{array}$ & $\begin{array}{c}127.4^{* * *} \\
(2.48 \mathrm{e}-10)\end{array}$ & $\begin{array}{c}0.627^{* * *} \\
(6.02 \mathrm{e}-10)\end{array}$ & 0.00 & $\begin{array}{c}3.679^{* * *} \\
(3.85 \mathrm{e}-06)\end{array}$ \\
\hline Observations & 155 & 159 & 159 & 156 & 159 & 155 & 155 \\
\hline R-squared & 0.032 & 0.020 & 0.041 & 0.010 & 0.032 & 0.055 & 0.034 \\
\hline$F$ test $p$ value & 0.259 & 0.516 & 0.00883 & 0.362 & 0.0817 & 0.00613 & 0.380 \\
\hline
\end{tabular}

p-values in parentheses, standard errors clustered at village level output and inputs in kgs per acre, education is years completed $* * * \mathrm{p}<0.01,{ }^{* *} \mathrm{p}<0.05,{ }^{*} \mathrm{p}<0.1$ 


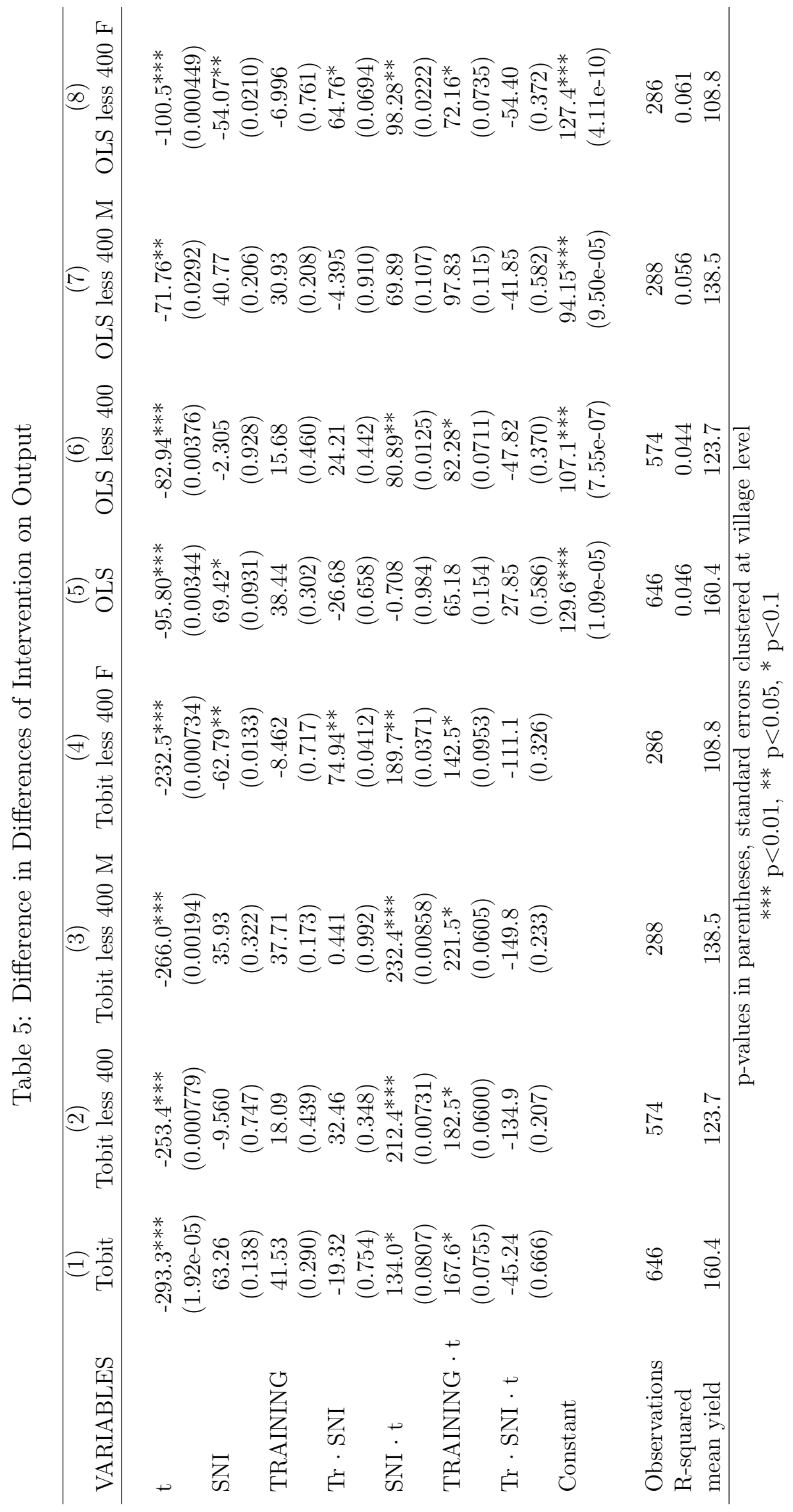




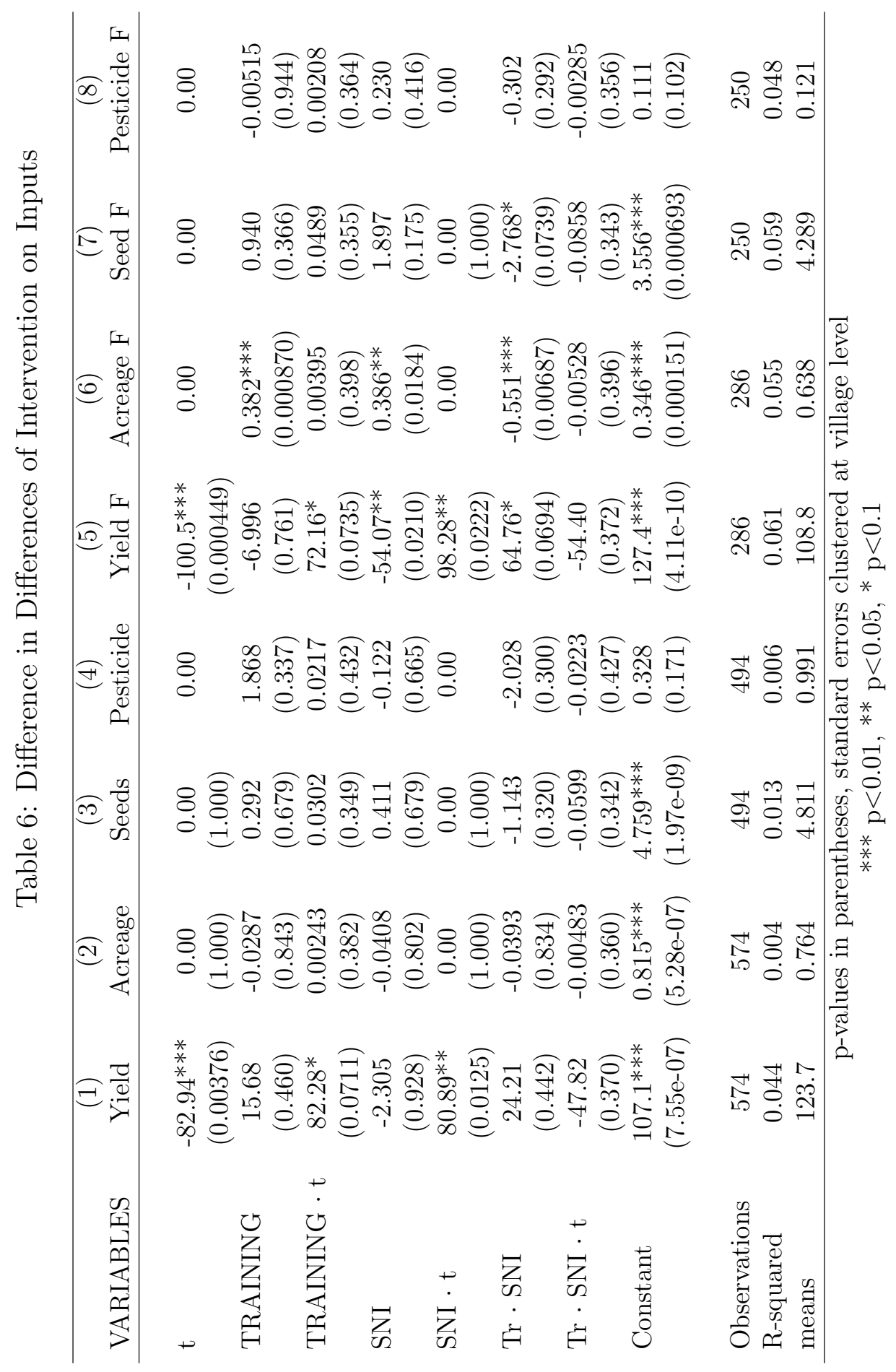


Table 7: Probit: Decision to Grow Cotton

\begin{tabular}{lcccc}
\hline & $(1)$ & $(2)$ & $(3)$ & $(4)$ \\
VARIABLES & All yields & yields less 400 & yields less $400 \mathrm{M}$ & yields less 400 F \\
\hline & & & & \\
SNI & $0.182^{*}$ & $0.256^{* *}$ & 0.173 & $0.385^{* * *}$ \\
TRAINING & $(0.0725)$ & $(0.0108)$ & $(0.141)$ & $(0.00439)$ \\
& 0.109 & 0.128 & 0.0633 & $0.249^{* *}$ \\
Tr $\cdot$ SNI & $(0.205)$ & $(0.144)$ & $(0.571)$ & $(0.0266)$ \\
& 0.0406 & -0.0281 & 0.114 & -0.205 \\
Observations & $(0.782)$ & $(0.858)$ & $(0.419)$ & $(0.342)$ \\
mean probability cultivated & 0.723 & 287 & 144 & 143 \\
\hline
\end{tabular}

p-values in parentheses, standard errors clustered at village level *** $\mathrm{p}<0.01,{ }^{* *} \mathrm{p}<0.05,{ }^{*} \mathrm{p}<0.1$ 
Table 8: Probit, Probability of Positive Yield for Planters in 2010

\begin{tabular}{lcccc}
\hline & $(1)$ & $(2)$ & $(3)$ & $(4)$ \\
VARIABLES & All yields & yields less 400 & yields less $400 \mathrm{M}$ & yields less $400 \mathrm{~F}$ \\
\hline & & & & \\
SNI & $0.188^{* *}$ & $0.195^{*}$ & $0.247^{* * *}$ & 0.147 \\
& $(0.0419)$ & $(0.0522)$ & $(0.00741)$ & $(0.279)$ \\
TRAINING & 0.121 & 0.157 & $0.189^{* *}$ & 0.117 \\
& $(0.161)$ & $(0.111)$ & $(0.0117)$ & $(0.463)$ \\
Observations & 235 & 205 & 107 & 98 \\
mean probability harvested & 0.804 & 0.785 & 0.813 & 0.755 \\
\hline
\end{tabular}

p-values in parentheses, standard errors clustered at village level ${ }^{* * *} \mathrm{p}<0.01,{ }^{* *} \mathrm{p}<0.05,{ }^{*} \mathrm{p}<0.1$ 
Table 9: Cross Sectional Impact of SNI on Yields and Information Learned

\begin{tabular}{lccc}
\hline & $(1)$ & $(2)$ & $(3)$ \\
MODELS & Tobit & OLS & OLS \\
VARIABLES & yield & yield & information learned \\
\hline \multirow{2}{*}{ SNI } & $134.9^{* *}$ & $51.06^{*}$ & $0.0601^{* *}$ \\
& $(0.0302)$ & $(0.0884)$ & $(0.0320)$ \\
TRAINING & $105.1^{*}$ & $46.77^{*}$ & 0.0298 \\
& $(0.0803)$ & $(0.0825)$ & $(0.218)$ \\
Tr $\cdot$ SNI & -47.89 & -6.737 & -0.0444 \\
& $(0.567)$ & $(0.875)$ & $(0.270)$ \\
Constant & $-96.42^{* *}$ & $32.15^{* *}$ & $0.380 * *$ \\
& $(0.0284)$ & $(0.0417)$ & $(0.00)$ \\
Observations & 273 & 273 & 273 \\
R-squared & \multicolumn{4}{c}{0.072} & 0.024 \\
mean & 84.96 & 84.96 & 0.415 \\
\hline p-values in parentheses, standard errors clustered at village level & &
\end{tabular}


Table 10: Impact of SNI on Yields,

Controlling for Attendance at the Information Meetings

\begin{tabular}{|c|c|}
\hline MODELS & $\begin{array}{c}(1) \\
\text { OLS }\end{array}$ \\
\hline $\mathrm{t}$ & $\begin{array}{c}-100.5^{* * *} \\
(0.000466)\end{array}$ \\
\hline SNI & $\begin{array}{l}-84.76^{* * *} \\
(0.000312)\end{array}$ \\
\hline TRAINING & $\begin{array}{l}-9.655 \\
(0.678)\end{array}$ \\
\hline $\mathrm{Tr} \cdot \mathrm{SNI}$ & $\begin{array}{l}77.25^{* *} \\
(0.0262)\end{array}$ \\
\hline $\mathrm{SNI} \cdot \mathrm{t}$ & $\begin{array}{l}108.4^{* *} \\
(0.0304)\end{array}$ \\
\hline TRAINING $\cdot \mathrm{t}$ & $\begin{array}{c}73.01^{*} \\
(0.0739)\end{array}$ \\
\hline $\mathrm{Tr} \cdot \mathrm{SNI} \cdot \mathrm{t}$ & $\begin{array}{l}-58.21 \\
(0.351)\end{array}$ \\
\hline Info & $\begin{array}{l}39.21^{* * *} \\
(0.00338)\end{array}$ \\
\hline Info $\cdot t$ & $\begin{array}{l}-12.98 \\
(0.720)\end{array}$ \\
\hline Constant & $\begin{array}{c}127.4^{* * *} \\
(4.41 \mathrm{e}-10)\end{array}$ \\
\hline $\begin{array}{l}\text { Observations } \\
\text { R-squared } \\
\text { mean yield }\end{array}$ & $\begin{array}{c}286 \\
0.071 \\
108.8\end{array}$ \\
\hline
\end{tabular}

p-values in parentheses, standard errors clustered at village level

Information indicates whether a women attended the information meeting.

Data include only females (no males were invited to the information meetings). *** $\mathrm{p}<0.01,{ }^{* *} \mathrm{p}<0.05,{ }^{*} \mathrm{p}<0.1$ 
A Additional Tables 


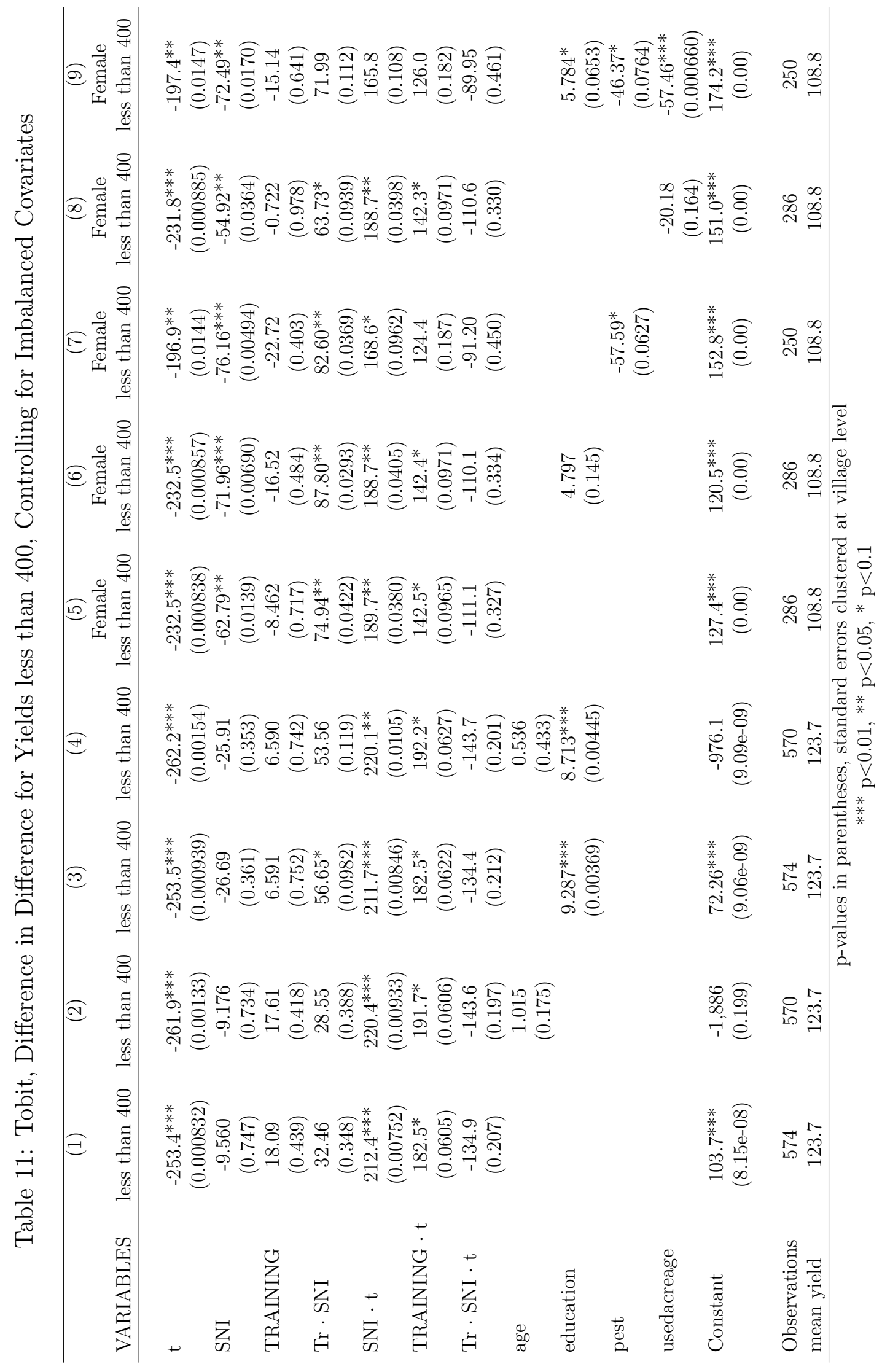


Table 12: OLS, Difference in Difference for Yields less than 400, Controlling for Imbalanced Covariates

\section{(1)}

$(2)$

$(3)$

$(4)$

(5)

Female

$(6)$

Female

Female

than 400 less than 400 less than 400 YA

\begin{tabular}{|c|c|c|c|c|c|c|c|c|c|}
\hline $\mathrm{t}$ & $\begin{array}{c}-82.94^{* * *} \\
(0.00376)\end{array}$ & $\begin{array}{c}-83.12^{* * *} \\
(0.00458)\end{array}$ & $\begin{array}{c}-82.94^{* * *} \\
(0.00379)\end{array}$ & $\begin{array}{c}-83.12^{* * *} \\
(0.00462)\end{array}$ & $\begin{array}{l}-100.5^{* * *} \\
(0.000449)\end{array}$ & $\begin{array}{l}-100.5^{* * *} \\
(0.000458)\end{array}$ & $\begin{array}{c}-104.7^{* * *} \\
(0.00556)\end{array}$ & $\begin{array}{l}-100.5^{* * *} \\
(0.000458)\end{array}$ & $\begin{array}{c}-104.7^{* * *} \\
(0.00573)\end{array}$ \\
\hline SNI & $\begin{array}{l}-2.305 \\
(0.928)\end{array}$ & $\begin{array}{l}-2.232 \\
(0.924)\end{array}$ & $\begin{array}{l}-15.44 \\
(0.549)\end{array}$ & $\begin{array}{l}-15.12 \\
(0.540)\end{array}$ & $\begin{array}{c}-54.07^{* *} \\
(0.0210)\end{array}$ & $\begin{array}{c}-60.95^{* *} \\
(0.0130)\end{array}$ & $\begin{array}{c}-69.67^{* *} \\
(0.0145)\end{array}$ & $\begin{array}{l}-46.50^{*} \\
(0.0539)\end{array}$ & $\begin{array}{c}-66.81^{* *} \\
(0.0299)\end{array}$ \\
\hline TRAINING & $\begin{array}{l}15.68 \\
(0.460)\end{array}$ & $\begin{array}{l}15.25 \\
(0.442)\end{array}$ & $\begin{array}{c}6.990 \\
(0.713)\end{array}$ & $\begin{array}{c}6.884 \\
(0.708)\end{array}$ & $\begin{array}{l}-6.996 \\
(0.761)\end{array}$ & $\begin{array}{l}-12.86 \\
(0.578)\end{array}$ & $\begin{array}{l}-20.90 \\
(0.455)\end{array}$ & $\begin{array}{c}0.504 \\
(0.984)\end{array}$ & $\begin{array}{l}-14.21 \\
(0.667)\end{array}$ \\
\hline $\mathrm{Tr} \cdot \mathrm{SNI}$ & $\begin{array}{c}24.21 \\
(0.442)\end{array}$ & $\begin{array}{c}21.35 \\
(0.483)\end{array}$ & $\begin{array}{c}42.58 \\
(0.178)\end{array}$ & $\begin{array}{c}40.41 \\
(0.201)\end{array}$ & $\begin{array}{c}64.76^{*} \\
(0.0694)\end{array}$ & $\begin{array}{c}74.30^{*} \\
(0.0530)\end{array}$ & $\begin{array}{c}77.42^{*} \\
(0.0574)\end{array}$ & $\begin{array}{c}53.96 \\
(0.142)\end{array}$ & $\begin{array}{c}68.33 \\
(0.131)\end{array}$ \\
\hline $\mathrm{SNI} \cdot \mathrm{t}$ & $\begin{array}{l}80.89^{* *} \\
(0.0125)\end{array}$ & $\begin{array}{l}81.07^{* *} \\
(0.0141)\end{array}$ & $\begin{array}{l}80.89^{* *} \\
(0.0126)\end{array}$ & $\begin{array}{l}81.07^{* *} \\
(0.0142)\end{array}$ & $\begin{array}{l}98.28^{* *} \\
(0.0222)\end{array}$ & $\begin{array}{l}98.28^{* *} \\
(0.0224)\end{array}$ & $\begin{array}{l}109.6^{* *} \\
(0.0323)\end{array}$ & $\begin{array}{l}98.28^{* *} \\
(0.0224)\end{array}$ & $\begin{array}{c}109.6^{* *} \\
(0.0329)\end{array}$ \\
\hline TRAINING $\cdot \mathrm{t}$ & $\begin{array}{c}82.28^{*} \\
(0.0711)\end{array}$ & $\begin{array}{c}82.80 * \\
(0.0733)\end{array}$ & $\begin{array}{c}82.31^{*} \\
(0.0713)\end{array}$ & $\begin{array}{c}82.86^{*} \\
(0.0734)\end{array}$ & $\begin{array}{c}72.16^{*} \\
(0.0735)\end{array}$ & $\begin{array}{c}72.28^{*} \\
(0.0736)\end{array}$ & $\begin{array}{c}83.72^{*} \\
(0.0850)\end{array}$ & $\begin{array}{c}72.24^{*} \\
(0.0738)\end{array}$ & $\begin{array}{c}84.18^{*} \\
(0.0844)\end{array}$ \\
\hline $\operatorname{Tr} \cdot \mathrm{SNI} \cdot \mathrm{t}$ & $\begin{array}{l}-47.82 \\
(0.370)\end{array}$ & $\begin{array}{l}-48.18 \\
(0.371)\end{array}$ & $\begin{array}{l}-47.93 \\
(0.370)\end{array}$ & $\begin{array}{l}-48.40 \\
(0.370)\end{array}$ & $\begin{array}{l}-54.40 \\
(0.372)\end{array}$ & $\begin{array}{c}-54.71 \\
(0.371)\end{array}$ & $\begin{array}{l}-63.35 \\
(0.354)\end{array}$ & $\begin{array}{l}-54.50 \\
(0.372)\end{array}$ & $\begin{array}{l}-64.21 \\
(0.350)\end{array}$ \\
\hline age & & $\begin{array}{c}0.749 \\
(0.221)\end{array}$ & & $\begin{array}{c}0.391 \\
(0.480)\end{array}$ & & & & & \\
\hline education & & & $\begin{array}{l}6.936^{* * *} \\
(0.00961)\end{array}$ & $\begin{array}{l}6.528^{* *} \\
(0.0103)\end{array}$ & & $\begin{array}{c}3.502 \\
(0.184)\end{array}$ & & & $\begin{array}{c}4.405 \\
(0.106)\end{array}$ \\
\hline pest & & & & & & & $\begin{array}{l}-16.87 \\
(0.107)\end{array}$ & & $\begin{array}{l}-12.30 \\
(0.245)\end{array}$ \\
\hline usedacreage & & & & & & & & $\begin{array}{c}-19.61^{*} \\
(0.0916)\end{array}$ & $\begin{array}{r}-47.22^{\text {*** }} \\
(0.00255)\end{array}$ \\
\hline Constant & $\begin{array}{c}107.1^{* * *} \\
(7.55 \mathrm{e}-07)\end{array}$ & $\begin{array}{c}-1,362 \\
(0.256)\end{array}$ & $\begin{array}{c}83.75 * * * \\
(6.05 \mathrm{e}-05)\end{array}$ & $\begin{array}{l}-680.2 \\
(0.531)\end{array}$ & $\begin{array}{c}127.4^{* * *} \\
(4.11 \mathrm{e}-10)\end{array}$ & $\begin{array}{c}122.4^{* * *} \\
(4.71 \mathrm{e}-09)\end{array}$ & $\begin{array}{c}148.3^{* * *} \\
(2.73 \mathrm{e}-08)\end{array}$ & $\begin{array}{c}134.2^{* * *} \\
(1.22 \mathrm{e}-09)\end{array}$ & $\begin{array}{c}166.9^{* * * *} \\
(3.37 \mathrm{e}-07)\end{array}$ \\
\hline Observations & 574 & 570 & 574 & 570 & 286 & 286 & 250 & 286 & 250 \\
\hline R-squared & 0.044 & 0.047 & 0.066 & 0.066 & 0.061 & 0.069 & 0.060 & 0.068 & 0.104 \\
\hline mean yield & 123.7 & 123.7 & 123.7 & 123.7 & 108.8 & 108.8 & 108.8 & 108.8 & 108.8 \\
\hline
\end{tabular}


Table 13: Difference in Differences of Intervention on Yields, Wild Bootstrapped SEs

\begin{tabular}{lcccc}
\hline & $(1)$ & $(2)$ & $(3)$ & $(4)$ \\
VARIABLES & OLS & OLS Less 400 & OLS less 400 M & OLS less 400 F \\
\hline & & & & \\
$\mathrm{t}$ & -95.80 & -82.94 & -71.76 & -100.5 \\
TRAINING & 0.115 & 0.255 & 0.135 & 0.13 \\
& 38.44 & 15.68 & 30.93 & -6.996 \\
TRAINING $\cdot \mathrm{t}$ & 0.405 & 0.545 & 0.385 & 0.765 \\
& 65.18 & 82.28 & 97.83 & 72.16 \\
SNI & 0.19 & 0.15 & 0.12 & 0.115 \\
& 69.42 & -2.305 & 40.77 & $-54.07^{*}$ \\
SNI $\cdot \mathrm{t}$ & 0.17 & 0.91 & 0.305 & 0.08 \\
& -0.708 & 80.89 & 69.89 & $98.28^{*}$ \\
Tr $\cdot$ SNI & 0.96 & 0.1 & 0.145 & 0.075 \\
& -26.68 & 24.21 & -4.395 & $64.76^{*}$ \\
Tr $\cdot$ SNI $\cdot \mathrm{t}$ & 0.695 & 0.425 & 0.975 & 0.09 \\
& 27.85 & -47.82 & -41.85 & -54.40 \\
Constant & 0.64 & 0.49 & 0.655 & 0.405 \\
& $129.6^{* * *}$ & $107.1^{* * *}$ & 94.15 & $127.4^{* * *}$ \\
Observations & $(0.00)$ & $(0.00)$ & 0.13 & $(0.00)$ \\
R-squared & 646 & 574 & 288 & 286 \\
mean yield & 0.046 & 0.044 & 0.056 & 0.061 \\
\hline
\end{tabular}

p-values in parentheses, standard errors clustered at village level

$$
* * * \mathrm{p}<0.01,{ }^{* *} \mathrm{p}<0.05, * \mathrm{p}<0.1
$$


Table 14: Main OLS Difference in Difference with Fixed Effects

\begin{tabular}{lcccc}
\hline & $(1)$ & $(2)$ & $(3)$ & $(4)$ \\
VARIABLES & All yields & yields less 400 & yields M less 400 & yields F less 400 \\
\hline & & & & \\
SNI & 0.0938 & $80.89^{* *}$ & 69.89 & $98.28^{* *}$ \\
& $(0.998)$ & $(0.0123)$ & $(0.106)$ & $(0.0215)$ \\
TRAINING & 65.64 & $82.09^{*}$ & 97.83 & $71.81^{*}$ \\
& $(0.152)$ & $(0.0708)$ & $(0.113)$ & $(0.0736)$ \\
Tr $\cdot$ SNI & 29.41 & -47.10 & -41.85 & -53.40 \\
& $(0.569)$ & $(0.376)$ & $(0.580)$ & $(0.378)$ \\
year & $-95.80^{* * *}$ & $-82.94^{* * *}$ & $-71.76^{* *}$ & $-100.5^{* * *}$ \\
& $(0.00338)$ & $(0.00369)$ & $(0.0284)$ & $(0.000425)$ \\
Constant & $192,651^{* * *}$ & $166,751^{* * *}$ & $144,289^{* *}$ & $202,052^{* * *}$ \\
& $(0.00335)$ & $(0.00366)$ & $(0.0283)$ & $(0.000423)$ \\
Observations & & & & \\
R-squared & 646 & 574 & 288 & 286 \\
Number of hhdid & 325 & 0.025 & 0.029 & 0.049 \\
mean yield & 160.4 & 287 & 144 & 143 \\
\hline
\end{tabular}

p-values in parentheses, standard errors clustered at village level ${ }^{* * *} \mathrm{p}<0.01,{ }^{* *} \mathrm{p}<0.05,{ }^{*} \mathrm{p}<0.1$ 


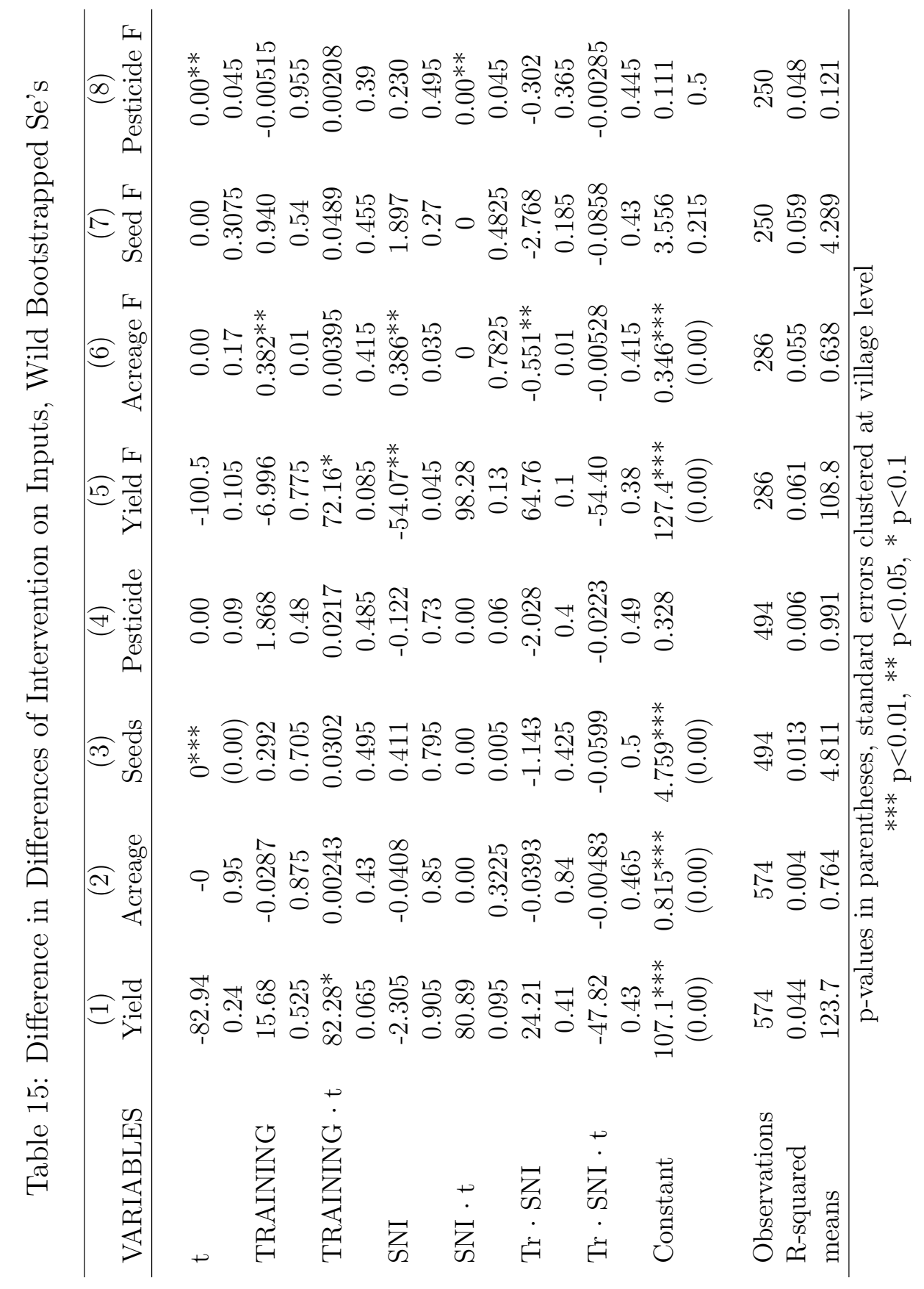




\section{B Information points in Training and SNI}

\section{Appendix: Game Points}

1. Ladybirds are good insects (show picture)

2. Spacing between rows is $75 \mathrm{~cm}$ (3 sheets long)

3. Spacing between plants is $30 \mathrm{~cm}$ long (1 sheet)

4. Only plant 3-5 seeds per hole

5. More than 2 seedlings in one place will reduce cotton yield

6. First weeding occurs between the 2nd and 3rd week after planting

7. Second weeding occurs between the 6 th and 10 th week after planting

8. Bollworm (show picture) larvae appears between the 8th and 9th week after planting

9. Check germination after 5 days-replants seeds at gaps to get even crop cover

10. Prepare land several weeks in advance for cotton planting

11. Cotton is good for mixed and rotational crop

12. Use pesticide 5 th to 7 th week after planting for Lygus bug (show picture)

13. Use pesticide 8 th to 9 th week after planting for Bollworm (show picture)

14. Always cover hands and mouth when spraying pesticides

\section{Appendix: Model}

To demonstrate our hypothesis that weak ties can improve yields, we use a simple modification to the standard target-input learning model [Foster and Rosenzweig, 1995, Jovanovic and Nyarko, 1996]. Households in this setting are growing cotton without the benefit of significant previous experience due to the interruption caused by civil war. We expect households to learn by doing (learning from their own experiences) as well as from the experiences of others in their community or from agricultural extension agents. Female-headed households experience lower yields in part because they have fewer opportunities to learn from others, and they may not be able to take full advantage of the training offered by extension officers. In particular, women may have fewer 
weak ties than men because their networks are more geographically concentrated and search costs for valuable ties may therefore be higher.

The conventional exposition of the target-input model focuses on the choice of input levels (such as fertilizer). However, in the Uganda setting, the greatest opportunities for learning are on issues of timing. Fertilizers are not generally used in cotton farming in this setting. Farmers are learning when to prepare, plant, thin, weed, apply pesticides, and harvest. ${ }^{21}$ The farmer chooses an input level (or, in our case, a time to apply inputs), $\theta_{i t}$, in order to maximize profits (see appendix D for more detailed exposition of this model). Profits are larger when the farmer's timing is closer to the ideal timing for a particular field in a particular year, $\tau_{i t}$. Profit $q$ for farmer $i$ in period $t$ is

$$
q_{i t}=1-\left(\theta_{i t}-\tau_{i t}\right)^{2}
$$

$\tau_{i t}$, the correct timing or input, is a normally distributed random variable $\left(\tau_{i t}=\tau^{\star}+\mu_{i t}\right.$ : $\left.\mu \sim N\left(0, \sigma_{\tau}^{2}\right)\right)$. The most profitable choice of timing or input is $\tau_{i t}$, but this is unknown and therefore, the farmer will seek to maximize profit by learning and then choosing $\tau^{\star}$. After choosing the timing, given the best available information, the farmer can observe the output and infer what the correct timing would have been for that time period. The farmer uses this noisy observation of $\tau^{\star}$ to update his or her beliefs over $\tau^{\star}$ from $\theta_{t}$ to $\theta_{t+1} \cdot{ }^{22}$ In the next period the farmer will choose the expectation of the posterior distribution as the new input level in period $t+1$.

The precision of the farmer's estimate of the target improves as the farmer observes more outcomes and updates the estimate with each new outcome. Denoting the number of outcomes observed at time $t$ as $S_{t-1}$ the variance of the farmer's estimate is derived from straightforward application of Bayes's rule:

$$
\sigma_{\theta_{t}}^{2}=\frac{1}{\rho_{\theta t=0}+\rho_{\tau} S_{t-1}}
$$

\footnotetext{
${ }^{21}$ The monitoring reports from trainers in the TR intervention contain information on what farmers said they spoke about to other farmers. The most commonly reported conversations are focused on timing issues. Farmers complain about inadequate access to pesticides and fertilizers but they do not talk about application levels [see Conley and Udry, 2010, for more about typical farmer information exchanges].

${ }^{22}$ In the pure target-input model, farmers observe $\tau$ directly, as a type of signal. Here we suggest that they infer it. The difference is that mathematical inference only gives us $\tau_{i t}=\theta_{i t} \pm \sqrt{1-q_{i t}}$. However, by assuming farmers have access to some additional information that allows them to know if their guess is above or below the optional level, these two views of a signal are formally identical.
} 
where $\rho_{\theta t=0}$ is the precision (inverse of the variance) of a farmer's estimate in the initial period and $\rho_{\tau}$ is the precision of the observations of the target timing $\left(\rho_{\tau}=\frac{1}{\sigma_{\tau}^{2}}\right)$. The expected ouput $\left(E_{t}\left(q_{i t}\right)=1-\sigma_{\theta_{t}}^{2}-\sigma_{\tau}^{2}\right)$ depends on the variance of the ex ante best timing $\left(\sigma_{\tau}^{2}\right)$, which does not change over time and the variance of the farmer's estimate $\left(\sigma_{\theta_{t}}^{2}\right)$, which falls over time, resulting in increased expected profits.

In the target input model, farmers do not experiment on their own plots for two key reasons. First, choosing any timing that is not the best guess of the target timing results in lower expected production. Thus, there is significant cost to experimentation. Second, different timing of actions does not provide new information: there is only one informative signal per plot. ${ }^{23}$ Experimenting within the plot does not provide new information but if the farmer can observe the choices of other farmers, that information can be used to update to her beliefs on the optimal timing. Assume that the farmer can observe or infer her neighbor's signal $\tau$ in period $t$, plus some additional reporting noise $\xi\left(\tau_{j}=\tau^{\star}+\mu_{j}+\xi_{i j}\right)$. Thus they see a signal with precision $\rho_{\nu}=1 / \sigma_{\nu}^{2}=1 /\left(\sigma_{\tau}^{2}+\sigma_{\xi}^{2}\right)$, where $\sigma_{\tau}^{2}$ is the variance of the state of nature and $\sigma_{\xi}^{2}$ is the variance of the observation of one's neighbors signal. The variance of the farmer's guess evolves as follows:

$$
\sigma_{\theta_{t}}^{2}=\frac{1}{\rho_{\theta t=0}+\rho_{\tau} S_{t-1}+\rho_{\nu} N_{t-1}}
$$

where $N_{t-1}$ is the total number of trials of other farmers observed at period $t$. Expected output is now a function of learning by doing $\left(S_{t}\right)$ and learning from others $\left(N_{t}\right){ }^{24}$

However, if a farmer cannot learn more by subdividing her plot, why does she learn from the experience of a neighbor whose plot is adjacent to hers? In particular, the experiences (signals) within one plot are likely to be correlated with the experiences of neighboring plots. Nearby plots are likely to suffer from highly correlated weather and pest events [in particular, pest spillovers: see Harper and Zilberman, 1989, Regev et al., 1976] meaning the signals received on two such plots are also correlated. To formalize this idea, assume that farmer $i$ observes farmer $j$ 's signal and that the new signal is correlated to farmer $i$ 's signal as described by $\gamma_{i j}$. Formally, the

\footnotetext{
${ }^{23} \mu_{i t}$ is identical across the whole plot, so while varying $\theta_{i t}$ across the plot changes $q_{i t}$, it does not provide new information. Dividing the plot gives multiple observations of one draw from a random variable, not multiple draws.

${ }^{24}$ Foster and Rosenzweig [1995] assume learning depends not on the number of neighbors but the hectares planted. Since hectares planted is not evolving in our model or data, we use the simplifying assumption that one farmer equals one observation.
} 
farmers sees a signal which is a weighted sum of her own signal and another, independent signal $\left(\tau_{j}=\gamma_{i j}\left(\tau^{\star}+\mu_{j}\right)+\left(1-\gamma_{i j}\right) \tau_{i}+\xi_{i j}\right)$. The parameter $\gamma \in(0,1]$ gives a measure of the spatial independence of states of nature over two plots where $\gamma_{i j}=1$ means the states of nature are uncorrelated and $\gamma_{i j}=0$ means they are perfectly correlated. ${ }^{25}$ We show in the appendix that $\sigma_{\nu}^{2}=\sigma_{\tau}^{2}+\sigma_{\xi}^{2} / \gamma_{i j}^{2}$, or $\sigma_{\tau}^{2}+1 / \rho_{\xi_{i j}} \gamma_{i j}^{2}$. Thus, the precision of a neighbor's signal is decreasing in the variance of the additional noise (increasing in the fidelity) $\sigma_{\xi}^{2}$ and increasing the independence of the signal $\gamma_{i j}{ }^{26}$

The variance of the farmer's guess now evolves in the following manner (where $\mathrm{J}$ is the set of possible network links and $\phi_{\xi}$ is the fidelity of a neighbor's signal, the inverse of the variance):

$$
\sigma_{\theta}^{2}=\frac{1}{\rho_{\theta t=0}+\rho_{\mu} S_{t-1}+\sum_{l=0}^{t-1} \sum_{k \in J} \frac{1}{\sigma_{\mu}^{2}+1 / \rho_{\xi i k} \gamma_{i k}^{2}}}
$$

Recall that

$$
E_{t}\left(q_{i t}\right)=1-\sigma_{\theta_{t}}^{2}-\sigma_{\tau}^{2}
$$

and we can see that

$$
\begin{array}{r}
\frac{\partial E q_{i t}}{\partial \gamma}>0 \quad \frac{\partial E q_{i t}}{\partial \rho_{\xi}}>0 \\
\frac{\partial^{2} E q_{i t}}{\partial \rho_{\xi_{i j}} \partial S}<0 \quad \frac{\partial^{2} E q_{i t}}{\partial \rho_{\xi_{i j}} \partial N_{-J}}<0 \quad \frac{\partial^{2} E q_{i t}}{\partial \rho_{\xi_{i j}} \partial \rho_{\theta t=0}}<0 \quad \frac{\partial^{2} E q_{i t}}{\partial \rho_{\xi_{i j}} \partial \gamma_{i j}}>0 \\
\text { where } \quad N_{-J}=\sum_{l=0}^{t-1} \sum_{k \notin J} \frac{1}{\sigma_{\mu}^{2}+1 / \rho_{\xi i k} \gamma_{i k}^{2}}
\end{array}
$$

In other words, network links with greater independence $(\gamma)$ and fidelity $(\xi)$ are more useful on average, and increasing the fidelity for a particular link $j$ is less useful for farmers who have already had the opportunity to learn (larger $S$ ), have otherwise better networks (larger $N_{-J}$ ), have a more precise prior about the correct timing of activities (greater $\rho_{\theta t=0}$ ) and that increasing

\footnotetext{
${ }^{25}$ Munshi [2004] generates variability in the usefulness of a neighbor's information by assuming farmer characteristics are heterogeneous; different farmers may be seeking different target input levels. In our specification, there is only one target input level, but nearby neighbors provide less unique information.

${ }^{26}$ Note that when $\gamma$ is zero, we have the same result as a farmer subdividing her own plot: nothing will be learned. When $\gamma$ is one, we have the standard learning result as above: the precision of a neighbor's signal is a function of the underlying variance of the state of nature and the variance that results from the noise in translating signals.
} 
the fidelity of a particular signal is more useful for links that have greater independence (greater $\left.\gamma_{i j}\right)$

Uncorrelated signals are useful for farmers because they provide a more precise signal of the optimal timing. Stronger network links, such as with nearby neighbors, imply more precise information flows but, following the intuition of Granovetter [1974], it may be that weaker links provide signals with greater independence and therefore information.

\section{Derivations}

Definitions of terms:

The farmer observes a signal $\tau$ drawn from $N\left(\tau^{\star}, \sigma_{\tau}^{2}\right)$. She has a prior over the true value of $\tau^{\star}$ distributed $N\left(\theta_{t}, \sigma_{\theta_{t}}^{2}\right)$. The signal and the prior are combined to create the posterior:

$$
\begin{array}{r}
N\left(\theta, \sigma_{\theta_{t}}^{2}\right) \Rightarrow N\left(\theta_{t+1}, \sigma_{\theta_{t+1}}^{2}\right) \\
\sigma_{\theta_{t}}^{2}=\frac{\sigma_{\theta_{t}}^{2} \sigma_{\tau}^{2}}{\sigma_{\theta_{t}}^{2}+\sigma_{\tau}^{2}} \theta_{t+1}=\frac{\sigma_{\theta_{t}}^{2}}{\sigma_{\theta_{t}}^{2}+\sigma_{\tau}^{2}} \tau+\frac{\tau}{\sigma_{\theta_{t}}^{2}+\sigma_{\tau}^{2}} \theta_{t}
\end{array}
$$

Introducing the notation for the precision $\rho=\frac{1}{\sigma^{2}}$ we can rewrite these as

$$
\begin{array}{r}
\sigma_{\theta_{t+1}}^{2}=1 / \rho_{\theta_{t+1}}=\frac{1}{\rho_{\theta_{t}}+\rho_{\tau}} \\
\theta_{t+1}=\frac{\rho_{\tau}}{\rho_{\theta_{t}}+\rho_{\tau}} \tau+\frac{\rho_{\theta}}{\rho_{\theta_{t}}+\rho_{\tau}} \theta_{t}
\end{array}
$$

Now in period $t+1$, the farmer observes a second signal $\tau_{t+1}$ and updates again, with resulting precision $\sigma_{\theta_{t+2}}^{2}=\frac{1}{\rho_{\theta_{t+1}}+\rho_{\tau}}=\frac{1}{\rho_{\theta_{t}}+2 * \rho_{\tau}}$. More generally, $\sigma_{\theta_{t}}^{2}=\frac{1}{\rho_{\theta_{t=0}}+S_{t-1} * \rho_{\tau}}$, where $S_{t-1}$ is the number of observations of neighbor's signals at time $t-1$.

When the farmer also observes the signals from other farmers $j, \tau_{i j t}=\tau_{j t}+\xi$. The variance of this new signal is $\sigma_{\nu}^{2}=\sigma_{\tau}^{2}+\sigma_{\xi}^{2}$ and finally combining own learning with learning from others, the variance of the prior evolves as follows: $\sigma_{\theta_{t}}^{2}=\frac{1}{\rho_{\theta_{t=0}}+S_{t-1} * \rho_{\tau}+N_{t-1} * \rho_{\nu}}$ where $N_{t-1}$ is the number of neighbor's signals observed at time $t-1$. 
Now assume that signals between two farmers $i$ and $j$ are correlated in the following fashion:

$$
\begin{aligned}
\tau_{i} & =\tau^{\star}+\mu_{i} \\
\tau_{j} & =\gamma_{i j}\left(\tau^{\star}+\mu_{j}\right)+\left(1-\gamma_{i j}\right) \tau_{i}+\xi_{i j}
\end{aligned}
$$

Essentially the signal from a neighbor is a weighted sum of the farmer's own signal, an uncorrelated (informative) signal and the standard noise associated with observing someone else's signal. However, the farmer knows $\gamma_{i j}$ and observes her own signal and can use this information to recover the uncorrelated (informative signal) from the observed signal.

$$
\frac{\tau_{j}-\tau_{i}\left(1-\gamma_{i j}\right)}{\gamma_{i j}}=\tau+\mu_{j}+\frac{\xi_{i j}}{\gamma_{i j}}
$$

The error associated with this new signal $\sigma_{\nu}^{2}$ is $\sigma_{\tau}^{2}+\frac{\sigma_{\xi_{i j}}^{2}}{\gamma_{i j}^{2}}$. In other words, although the farmer can extract an unbiased uncorrelated signal, the noise associated with this signal is greater than the noise associated with the pure uncorrelated signal and this noise is a function of the correlation between the two signals. Note that where $\gamma=1$ we have the same uncorrelated signal as before and when $\gamma=0$ we have a completely uninformative signal (with infinite variance). In general, because $\gamma \in(0,1]$, the error associated with this signal is greater than the error associated with an uncorrelated signal: $\sigma_{\mu}^{2}+\sigma_{\xi_{i j}}^{2}<\sigma_{\mu}^{2}+\frac{\sigma_{\xi_{i j}}^{2}}{\gamma_{i j}^{2}}$. 